University of Rhode Island

DigitalCommons@URI

Open Access Master's Theses

1997

\title{
Initiating Coastal Management in Kenya and Zanzibar, Tanzania: a strategic approach
}

Mark Amaral

University of Rhode Island

Follow this and additional works at: https://digitalcommons.uri.edu/theses

\section{Recommended Citation}

Amaral, Mark, "Initiating Coastal Management in Kenya and Zanzibar, Tanzania: a strategic approach" (1997). Open Access Master's Theses. Paper 504.

https://digitalcommons.uri.edu/theses/504

This Thesis is brought to you for free and open access by DigitalCommons@URI. It has been accepted for inclusion in Open Access Master's Theses by an authorized administrator of DigitalCommons@URI. For more information, please contact digitalcommons-group@uri.edu. 


\title{
Initiating Coastal Management in Kenya and Zanzibar, Tanzania:
} a strategic approach

By

\author{
Mark Amaral \\ A Research Project Submitted in \\ Partial Fulfillment of the Requirements \\ for the Degree of \\ Master of Community Planning
}

University of Rhode Island

1997 


\section{MASTER OF COMMUNITY PLANNING \\ RESEARCH PROJECT}

\section{OF}

MARK AMARAL

Approved By:

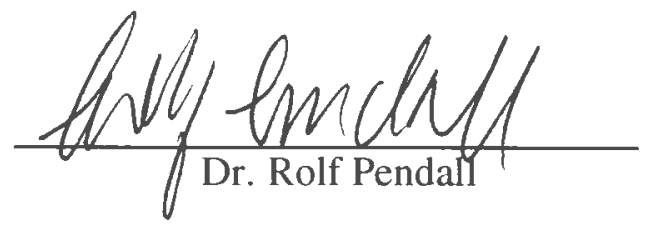

Major Professor Dr. Rolf Pendall

Acknowledged By:

Director

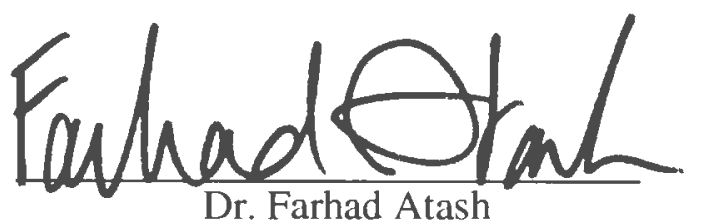




\section{ACKNOWLEDGMENTS}

I am grateful to the many people who have contributed in so many ways to my completion of this document. In particular, I want to express my appreciation to Dr. Rolf Pendall, my major professor, for his patience, persistence, and honesty. Without his timely and careful review of the drafts of this document, my graduation would have certainly been delayed. To my readers, Dr. Farhad Atash and Lynne Zeitlin Hale, for providing important input to previous drafts of this document and for their constant advise and assistance.

I would also particularly like to thank Lynne Hale, Virginia Lee and Dr. Marcia M. Feld for the influence they have had on my understanding about the process and practice of planning and coastal management.

Of course, I could not have completed this document or degree without my wife, Erin, and would like to thank her for reviewing this document, for her patience throughout my long graduate career and for her constant and unyielding support.

Finally, I would like to acknowledge and thank the Kenya and Zanzibar Integrated Coastal Management teams for making coastal management a reality in both countries. Their dedication and commitment to the process is truly making a difference. 


\section{TABLE OF CONTENTS}

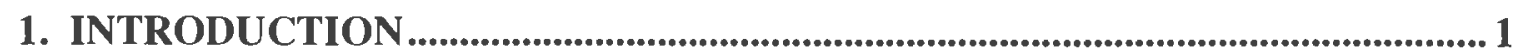

2. COMPREHENSIVE AND STRATEGIC PLANNING IN INTEGRATED

COASTAL MANAGEMENT .......................................................................... 4

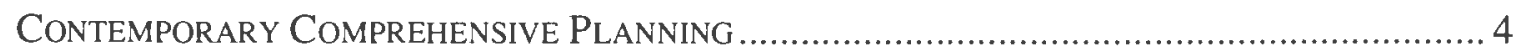

The Link Between Contemporary Comprehensive and Strategic Planning............... 9

ICM PRINCIPLES AND KEY ATTRIBUTES............................................................... I2

COMPARING ICM ANd CONTEMPORARY/STRATEGIC PLANNING ..................................... 18

3. EAST AFRICA PILOT PROJECT CASE STUDY ............................................ 21

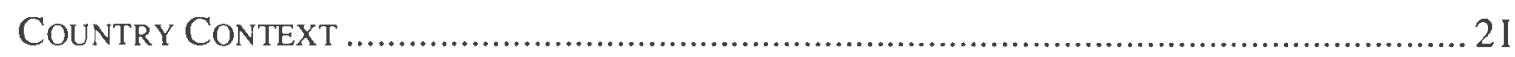

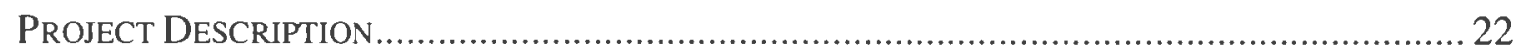

The Pilot Sites: Initiating Integrated Coastal Management in East Africa ......... 26

4. THE PROCESS AND TECHNIQUES USED IN THE EAST AFRICA PILOT

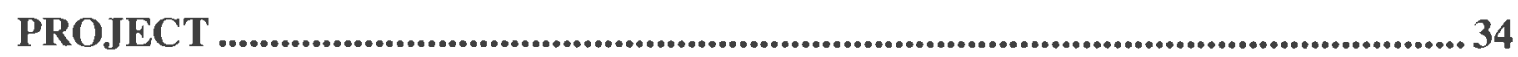

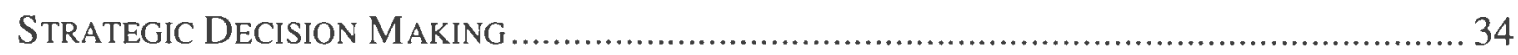

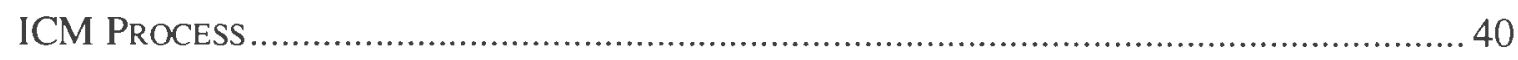

Intervention Techniques ApPlied by the Project ................................................... 53

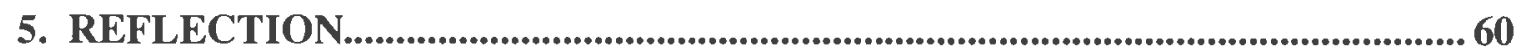

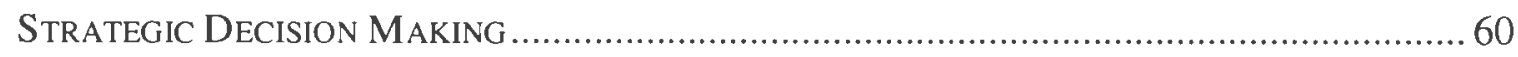

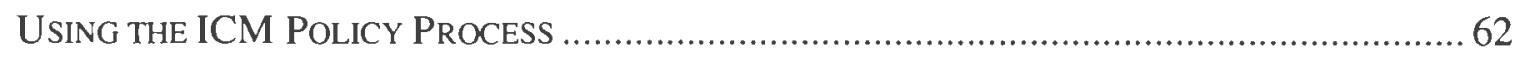

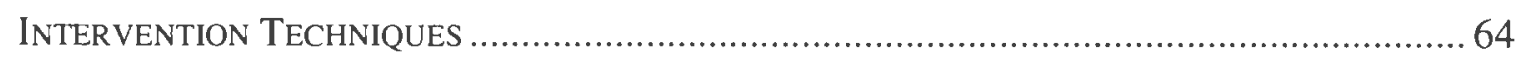

Contribution to Contemporary Comprehensive/Strategic Planning ....................... 66

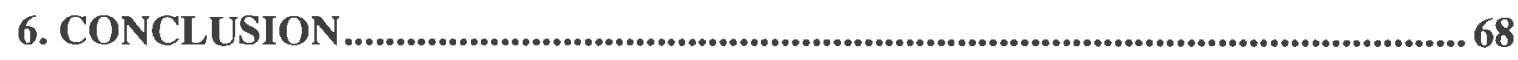

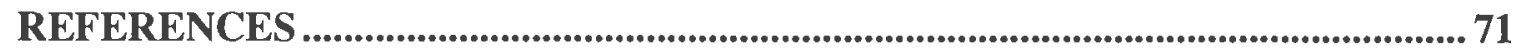




\section{LIST OF FIGURES, TABLES AND MAPS}

Figure 1 - Integrated Coastal Management Policy Process....................................... 17

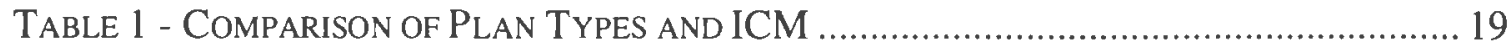

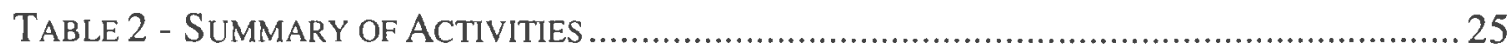

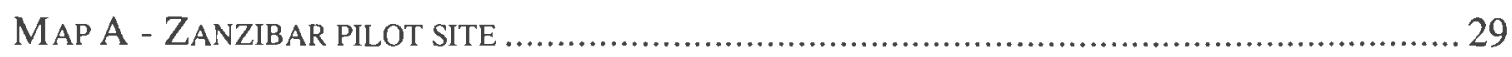

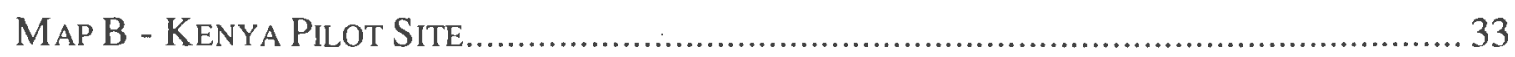

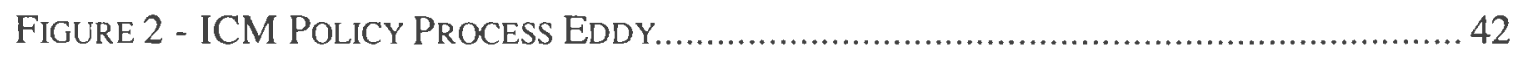




\section{INTRODUCTION}

Integrated Coastal Management (ICM) is a process that unites government and the community, science and management, sectoral and pubic interests to wisely protect and develop coastal ecosystems and resources. As funding for ICM continues to increase, investments are often made quickly, without adequate consultation with the stakeholders and host institutions. This can lead to programs and projects that lack focus and outstrip the host institution's capacity and capabilities. By thinking strategically about the current coastal management problems and pressures and developing a strategy document using an organized and strategic process, investment can be made wisely and at a scale that is sensible for the existing situation. Without this strategic thinking at the beginning of, and throughout the ICM process, investment in an institution is often made regardless of the institution's capacity to absorb the investment and is often directed at problems or pressures that have little salience to the local population or cannot be solved by the existing institutional structure. However, this strategic thinking must be done within the framework of a larger, more comprehensive process that attempts to achieve sustainable use of coastal resources over the long term. Therefore, it appears that for ICM to be successful, it must balance both strategic and comprehensive planning approaches.

This paper will demonstrate that ICM shares many of the attributes that are contained in contemporary comprehensive planning as described by Kaiser and Godschalk (1995) and Innes (1996). It will also show that ICM includes many of the critical attributes of strategic planning as described by Bryson (1988). Based on a review of current literature about comprehensive and strategic planning, this paper will highlight the areas where ICM supports the contemporary approach to comprehensive planning and will make a link between strategic planning, contemporary comprehensive planning and ICM. This 
paper will also describe how ICM was initiated in East Africa and how the contemporary/strategic approach to planning was used in that project which was conducted by the Coastal Resources Center (CRC) at the University of Rhode Island. A secondary objective of this paper is to document the approach and intervention techniques used in the East Africa ICM project.

This report addresses these questions in five chapters. The first chapter introduces current and past literature related to comprehensive planning and defines contemporary comprehensive planning as described in two recent journal articles. Contemporary planning is then linked to strategic planning and an argument is made for linking the two into one common approach termed contemporary/strategic planning. The practices and principles of ICM are then described, drawing heavily from a recently issued report by The Group of Experts on the Scientific Aspects of Marine Environmental Protection (GESAMP). ICM is then compared with contemporary/strategic planning. To demonstrate the key attributes of ICM that are closely related to contemporary/strategic planning, a case study is presented about an ICM project in East Africa. The third chapter provides background on the East Africa ICM project used by the case study. The fourth chapter describes how key ICM attributes were incorporated into the East Africa ICM project and discusses some of the technical assistance and intervention techniques used. The final chapter reflects back upon the East Africa ICM project and highlights the important elements of that project and how it contributed to a planner's understanding of contemporary/strategic planning.

The case study presented in this paper is about an ICM project in Kenya and Zanzibar conducted through a United States Agency for International Development (USAID) and United Nations Environmental Programme (UNEP). This intervention began the process of establishing an integrated coastal management program for each country and began 
building the necessary constituency and capacity for managing coastal resources at a scale and scope that matched the ability of the host institutions. The project attempted to achieve this goal by:

- working in a pilot site that contained a representative mix of coastal management problems and pressures to facilitate learning between the pilot and the national level

- building an intersectoral team for ICM and raising the capacity of its members

- completing the ICM policy process for the pilot site in an abbreviated time frame

- developing an ICM strategy document that identifies actions that could be taken immediately and future plans and actions that will be necessary to address coastal resource problems and pressures in the future.

This project was conducted under the umbrella of the UNEP - Regional Seas Programme's EAF/5 Project - Protection and Management of the Marine and Coastal Environment in the Eastern African Region. The ultimate objectives of the project were to develop within national institutions self-reliance on all matters relating to the integrated management of the coastal and marine environments and to ensure that there was a balance between environmental protection and resource use in the implementation of development opportunities (Akiwumi 1996). Support for the project was provided by USAID Regional Economic Development Service Office/East and South Africa (REDSO-ESA), USAID Global Office, UNEP and Food and Agricultural Organization (FAO). Technical assistance for the project was provided by the Coastal Resources Center (CRC) at the University of Rhode Island (URl). 
2. COMPREHENSIVE AND STRATEGIC PLANNING IN INTEGRATED COASTAL MANAGEMENT

\section{Contemporary Comprehensive Planning}

Two recent articles by Kaiser and Godschalk (1995) and Innes (1996) have re-opened the discussion about how comprehensive planning is achieved in today's planning environment. The approach for comprehensive planning is termed differently by each article. Kaiser and Godschalk call it "1990's hybrid design-policy-management plan" and Innes calls it "Planning through consensus building." Both articles are, fundamentally, discussing the same approach to comprehensive planning. They both find that comprehensive planning does exist, but the means and mechanisms for completing a comprehensive plan have shifted from an emphasis on land use maps and long term time horizons to a focus on planning as a participatory process which has a long and short term time horizons.

Kaiser and Godschalk's article provides an useful discussion that brings the different attributes of comprehensive planning together and clearly makes the argument that comprehensive planning still exists but its form and function have changed. The details of this argument are presented in a comparative table that compares features/attributes of plans to the contemporary prototype plans such as: 1950's general plan, land use design plans and development management plans (Kaiser and Godschalk 1995, 381). The attributes used for comparison between the plans include: land use maps, nature of recommendations, time horizon, link to implementation, public participation and environmental protection. This table clearly shows how hybrid plans draw from the different features of different plans. Innes' article supports the discussion presented by Kaiser and Godschalk and discusses many of the attributes described by Kaiser and 
Godschalk's hybrid model. Innes also adds several additional attributes - role of the planner, innovation and recognition of political power - to the contemporary comprehensive planning hybrid model. Kaiser and Godschalk's and Innes's contemporary comprehensive planning attributes, especially those that focus on planning as a process and the role of the planner as facilitator and expert, build from the earlier writings of Lindblom (1959) and Meyerson (1956).

Kaiser and Godschalk, after an extensive review of existing comprehensive land use plans, found that today's contemporary comprehensive plans "integrated the useful parts of each of the separate prototype plans" such as the land use design and classification plan, verbal policy plan, and the development management plan (1995, 377). They also find that the plans were "prepared with considerable participation by citizens and interest groups" and "such plans usually reflect animated political debates" (Kaiser and Godschalk 1995, 377). This planning approach allows the community to strategically select the planning time-frame, the issues that need to be addressed and the approach to addressing those issues. By having significant community participation, the final plan takes the form best suited for the community developed through a process where the planner serves as facilitator and expert.

Innes' article also focuses on community participation and consensus building in the planning process. She argues that this approach can lead to a comprehensive plan that “conforms with T. J. Kent's stipulations for the urban general plan" (Innes 1996, 469) and is practical and politically viable. This argument is made by addressing each of the points raised by Altshuler in his articles written in the mid 1960s (1965a, 1965b). In those articles, Altshuler suggests that "comprehensive planning is neither practical nor politically viable" (Innes 1996, 469). Innes finds that today's comprehensive plans, through consensus building, can be successfully created and implemented. This can be 
done, she argues, because local conditions for planning have changed since the time of Altshuler's writing. These changes include:

- the planner can serve as individual synthesizer and facilitator instead of an expert in the public interest.

- public interest does not need to be aggregate of individual desires, but can be found through consensus building.

- knowledge for planning can come from observable facts as well as “experiential, subjective, and socially shared knowledge" $(1996,463)$.

- "consensus building can bring together agencies and commissions" (1996, 463) for joint decision making within a fragmented city government.

- compared to the mid 1960's there are substantial organized interests that can effectively participate in the planning practices.

Because of these changes and the development of new planning methods, such as consensus building, Innes was able to form rebuttals to each of Altshuler's eight critiques of comprehensive planning. In essence, Innes finds that through consensus building and changes in the local planning context, today's plans, policies and guidelines "conform in significant ways to Kent's stipulation for the urban general plan" $(1996,469)$ while successfully remedying each of Altshuler's critiques.

Tension between comprehensive land use planning and more strategic planning approaches has existed since the 1950's. It was first raised by Meyerson in his article "Building the Middle-Range Bridge for Comprehensive Planning." In this article, Meyerson argues that planners should not abandon long-term comprehensive land use planning but should augment it with an "intermediate set of planning functions" (1956, 59). Although these "functions" still had heavy emphasis on producing plans and 
viewing the planner as technical expert, Meyerson's statement was the first step away from long-range planning and physical plans as comprehensive planning's only focus.

Lindblom, in "The Science of "Muddling Through", (1959), takes a course similar to the one charted by Meyerson. He presents an alternative to the rational comprehensive method of planning with what he termed the "successive limited comparisons" approach (Lindblom 1959, 81). This approach is based on the idea that long-term comprehensive planning is flawed because of the inherent lack of human and intellectual capacity to solve complex planning problems and, as a result, planners and public administrators practice a method that differs from the theory espoused by academics. This method "continually build[s] out from the current situation, step-by-step and by small degrees" (Lindblom 1959, 81). This incremental approach to planning provides a shorter-term view of the problems and places emphasis on agreement or consensus on possible solutions. Lindblom suggests that good policy is measured not by the eventual outcome of the policy but by "agreement on the policy" by various analysts $(1959,83)$. This tenet closely mirrors attributes in Innes's consensus building model, where the groups being studied all "reached agreement on significant products...and principles" (1996, 465). Lindblom also introduces the important concept of "succession of comparison" (1959, 86). This concept states that "policy is not made once and for all; it is made and re-made endlessly" (Lindblom 1959, 86). This important characteristic plays a critical role in both Kaiser and Godschalk's Hybrid Model and Innes's Consensus Building Model where process, not product, is key.

Friedmann added significant ammunition to the debate with his article "Towards a NonEuclidian Mode of Planning" in 1993. This article puts a heavy emphasis on a process for "bringing planning knowledge and practice to bear directly on the action itself" instead of "preparing documents" (Friedmann 1993, 482). Friedmann states that the new 
model of planning is "face-to-face interaction in real time" and focuses on "regional and local planning over national" $(1993,482)$. The article also outlines the attributes of nonEuclidian mode of planning that mirror many of the attributes of Kaiser and Godschalk, Innes and even several of the predecessors, such as Lindblom and Meyerson. These attributes of the new planning mode include:

- planning should be innovative, which requires it to be "consequently focused rather then comprehensive in scope; present rather than future oriented; and concerned chiefly with institutional and procedural changes appropriate to the case at hand" (1993: 483). Innes too found that planning needs to be innovative and, in fact, can be innovative through the consensus building process that facilitates input from the group interaction (Innes 1996, 469).

- planning should be political and should involve "strategies and tactics designed to overcome resistance to change" (Friedmann 1993: 483).

- planning should be transactive, wherein the role of the planner is that of facilitator to ensure a participatory and open process. This also mirrors Innes's ideas on consensus building and the key role that planners played in developing the plan through interaction with the stakeholders $(1996,467)$.

- Planning should be based on social learning that allows planners to "proceed cautiously and experimentally to learn from mistakes, to allow new information to guide the course of action, and to take immediate corrective actions as may be needed" $(1993,484)$. This aligns with the earlier thinking of Lindblom, whose ideas also supported "incremental change...[to] avoid serious lasting mistakes" $(1959,86)$.

Friedmann finds that comprehensive planning is "either dead or severely impaired" (1993, 484). This is far more extreme then the positions taken by Kaiser and Godschalk 
and lnnes which find that comprehensive planning does exist, but is achieved through different means and mechanisms compared to five decades ago. However, Friedmann's radical position does highlight the importance of today's planning practice to "operate in real time by linking knowledge and action into a tightly looped process of strategic change" $(1993,484)$. The key here is the focus on process and strategic decision making to induce change and a shift away from physical and land use plans as the outputs; many of the same arguments are made by Kaiser and Godschalk and Innes.

\section{The Link Between Contemporary Comprehensive and Strategic Planning}

The model that Kaiser and Godschalk call "Hybrid," Innes calls "Planning through Consensus Building," and even some of the earlier methods described by Lindblom, Meyerson and Friedmann, overlay with strategic planning. Bryson (1988) contends that there are fundamental differences between strategic and comprehensive planning. However, when his arguments about the differences between comprehensive and strategic planning are compared to the description of Kaiser and Godschalk's hybrid plans and Innes's consensus plans, the differences seem less apparent.

Bryson described strategic planning as "a disciplined effort to produce fundamental decisions and actions that shape and guide what an entity is, what it does, and why it does it" $(1988,5)$. He finds four differences between strategic and comprehensive planning. Each are listed below with appropriate rebuttals taken from Innes's and Kaiser and Godschalk's articles. 
1. Strategic planning is more action-oriented and more broadly participatory with a great focus on the community's strengths and weaknesses. Kaiser and Godschalk's review of hybrid plans found that the link to implementation and action in these plans ranges from moderate to strong, especially if the hybrid plan contains elements of a development management plan $(1995,381)$. Development management plans "feature a coordinated program of actions, supported by analyses and goals" (1995, 375).

2. Strategic planning rarely has legal status, unlike comprehensive plans which are usually legally binding. Although Kaiser and Godschalk found that local comprehensive plans were prepared under state growth management regulations, they also found that comprehensive plans went well beyond the legislative mandate to "provide a platform for the formation of community consensus" on a range of issues (1995, 365). Innes came to a similar conclusion that comprehensive planning provides a critical coordinating tool which extends beyond the framework of growth management regulation $(1996,467)$.

3. Visions that guide strategic planning usually involves actors; the visions that guide comprehensive plans usually exclude actors. Bryson simply defines "actors" as "typically, but not necessarily, organizations" $(1988,9)$. Innes clearly shows that actors are the core of the planning process $(1996,465)$ and Kaiser and Godschalk have found that contemporary hybrid plans have "considerable participation by citizens and interest groups" (1995, 381).

4. Comprehensive planning usually confines its agenda to a few government roles. Innes found that a key element of consensus-building planning was that it "cuts across agencies and commissions, brings together bureaucrats, elected officials, and 
citizens together for joint learning and decision making" $(1996,463)$. This "crosscutting" approach is employed to deal directly with the fact that the Progressive Reform Model of Government is sectoral and fragmented where "bureaucratic agencies [are] not designed to address the broad mission of planning" (Innes 1996, 453).

Comparing Bryson's views on strategic and comprehensive planning to those of Innes and Kaiser and Godschalk, it becomes apparent that the differences are not that extreme. In fact, the gap between strategic and comprehensive planning is closing rapidly, such that Kaiser and Godschalk found the influence of strategic planning "showing up across a range of contemporary comprehensive plans" $(1995,372)$. The gap is being closed because both planning approaches place a heavy emphasis on strategic decision making and planning as a process. Both approaches make a series of decisions based on the existing situation and resources available and follow a cyclical process that promotes learning and locally specific action. As these decisions are made and the planning process moves forward, different sets of tools and techniques are applied by strategic and comprehensive planners. But at the core, both processes are thinking and acting strategically; following a process that allows significant participation, cut across different government sectors and are action orientated. In fact, there is "little difference in the outcomes" between strategic and comprehensive planning (Bryson 1988, 8). Therefore, contemporary comprehensive planning and strategic planning are intertwined. This planning mixture could be referred to as contemporary/strategic planning. 


\section{ICM Principles and Key Attributes}

Integrated Coastal Management (ICM) is a process that unites government and the community, science and management, sectoral and pubic interests to wisely protect and develop coastal ecosystems and resources. To make progress on this goal, ICM employees many of the same attributes contained in the contemporary/strategic planning approach. For example, ICM relies heavily upon the process of planning and implementation, not the product, and a focus on strategic decision making throughout the process. This section will describe the practices and principles of ICM and demonstrate that key attributes of contemporary/strategic planning are closely related to ICM.

The notion of managing activities within the coastal area began in the United States with the passing of the Coastal Zone Act in 1972. The Act found that pressures in the nation's coastal zone were increasing at an alarming rate and that additional planning and management was necessary. The Act delegated the primary planning and management responsibility to each coastal state and provided incentives for states to prepare and implement coastal management plans.

In the mid-1980s, the United State's coastal management experience was taken to other countries by USAID and CRC. CRC provided key assistance to the state of Rhode Island during the development of the Rhode Island Coastal Resource Management Program (CRMP) and subsequent amendments. USAID contracted CRC as their primary advisor on coastal management and initiated three pilots sites around the world. These pilot sites in Ecuador, Sri Lanka and Thailand provided the laboratories where coastal management could be experimentally implemented outside of the United States. These three projects were part of a growing number of ICM projects being implemented around the world. In 1984 there were fourteen Integrated Coastal Management (ICM) efforts underway in 
thirteen nations (Sorensen, 1993). This was in addition to the 36 programs already underway in the United States. This number, according to Sorensen had expanded to 86 in 1990 (1993). The last count of ICM programs done by Sorensen was in 1993, when he found 142 programs initiated in 57 sovereign or semi-sovereign states. The number of ICM efforts currently underway has not been inventoried since 1993, but likely exceeds the number of programs active at that time.

The blossoming of ICM programs can be attributed to increased recognition at the international level that ICM is an effective management tool. One of the key international statements that supports and promotes ICM is Agenda 21 adopted at the United Nations Conference on Environment and Development in 1992. Chapter 17 addressees coastal management, by calling upon coastal states to:

- Provide for an integrated policy- and decision-making process... to promote compatible and balanced use of coastal resources;

- Identify existing and projected uses of coastal areas and their interactions;

- Concentrate on well-defined issues;

- Apply preventive and precautionary approaches in project planning and implementation, including prior assessment and systematic observation of the impacts of major projects;

- Promote the development and application of methods, such as natural resources and environmental accounting that reflects changes in value resulting from uses of coastal and marine areas, including pollution, marine erosion, loss of resources and habitat destruction; and 
- Provide access...for concerned individuals, groups, and organizations to relevant information and opportunities for consultation and participation in planning and decision making (UNEP 1992, Agenda 21).

These actions provide a global framework for coastal management and can be interpreted as principles for future ICM endeavors. These broad statements were given additional focus and clarity by the Joint Group of Experts on the Scientific Aspects of Marine Environmental Protection (GESAMP) who met from 1994 to 1996 to discuss the contributions of science to integrated coastal management.

Experts on the joint group represented agencies such as the United Nations, United Nations Environmental Programme, Food and Agriculture Organization of the United Nations, Intergovernmental Oceanographic Commission, World Health Organization, and the International Maritime Organization. The Joint Group of Experts, as part of their deliberations, developed a consensus on a ICM definition:

ICM is a process that unites government and the community, science and management, sectoral and public interests in preparing and implementing an integrated plan for the protection and development of coastal ecosystems and resources. The overall goal of ICM is to improve the quality of life of human communities who depend on coastal resources while maintaining the biological diversity and productivity of coastal ecosystems (GESAMP 1996).

This builds on earlier definitions, such as:

- ICM is a framework that combines all aspects of the physical, biological and human components of the coastal zone as defined by Pernetta and Elder (1993).

- ICM improves and maintains the quality of coastal regions to ensure a sustained flow of benefits to human societies and to improve the governance of coastal ecosystems (Crawford et al. 1995). 
ICM experts and practitioners are moving towards agreement on the principles and features of ICM. Olsen et al. (1996) reviewed the current literature including Chua 1993; Clark 1995; Pernetta and Elder 1993; World Bank 1993; and Post and Lundin 1996 and found that four principles can be identified for "effective coastal management." These are:

- local and national ownership of the program,

- stakeholder participation in all phases of the program,

- follow a policy process of issue identification, strategy development, adoption, implementation and evaluation, and

- strategic issue-driven program focus and decision making

The last two attributes, for the purpose of this paper, are key for several reasons. First, they mirror almost exactly the two key attributes in the contemporary/strategic planning approach. Second, they were critical during the implementation of the East Africa ICM project, and are the focus of the case study. Both of these attributes, as defined by ICM, are discussed in detail below.

\section{ICM Policy Process}

ICM follows a cyclical policy process which is often described using a series of interconnected steps. The steps along this process vary somewhat between programs and coastal management experts. Olsen et al. (1996) describe a five-step process (Figure 1) in "Coastal Management In Latin America and the Caribbean: Lessons Learned and Opportunities for the Inter-American Development Bank" and GESAMP (1996). These steps, defined as the policy process, include: 
1. Issue identification

2. Strategy Development

3. Adoption

4. Implementation

5. Evaluation.

The ICM process described by Olsen et al. (1996) takes between eight and 12 years to complete if the project's aim is to develop a national ICM program. Pernetta and Elder (1993) outline a seven step process that includes (1) problem definition, (2) assessment and analysis, (3) issues and options, (4) formulation, (5) adoption, (6) implementation, and (7) monitoring and evaluation. This process, too, takes about a decade to complete.

Regardless of the model used, the steps provide important guide posts for the ICM process and all the authors agree that the process is cyclical and that ICM programs have to move from one step to the next. The cyclic process allows learning in incremental stages thus allowing the practitioners to adjust the process as it proceeds. Of course there is porosity between the steps and there are many sub-steps or "activities" within each step. Feedback loops between the steps also exist. These feedback loops facilitate the flow of information between the steps in both directions -forward and back-allowing the ICM practitioner to learn, adjust the approach, apply and learn again. This learning approach mirrors Lindblom's "Muddling” approach to planning (1959). This interactiveness between steps is the function of a complex reality. This model is an attempt at simplifying that very complex reality but cannot definitively describe the process for developing a coastal management plan. 
Figure 1 - Integrated Coastal Management Policy Process

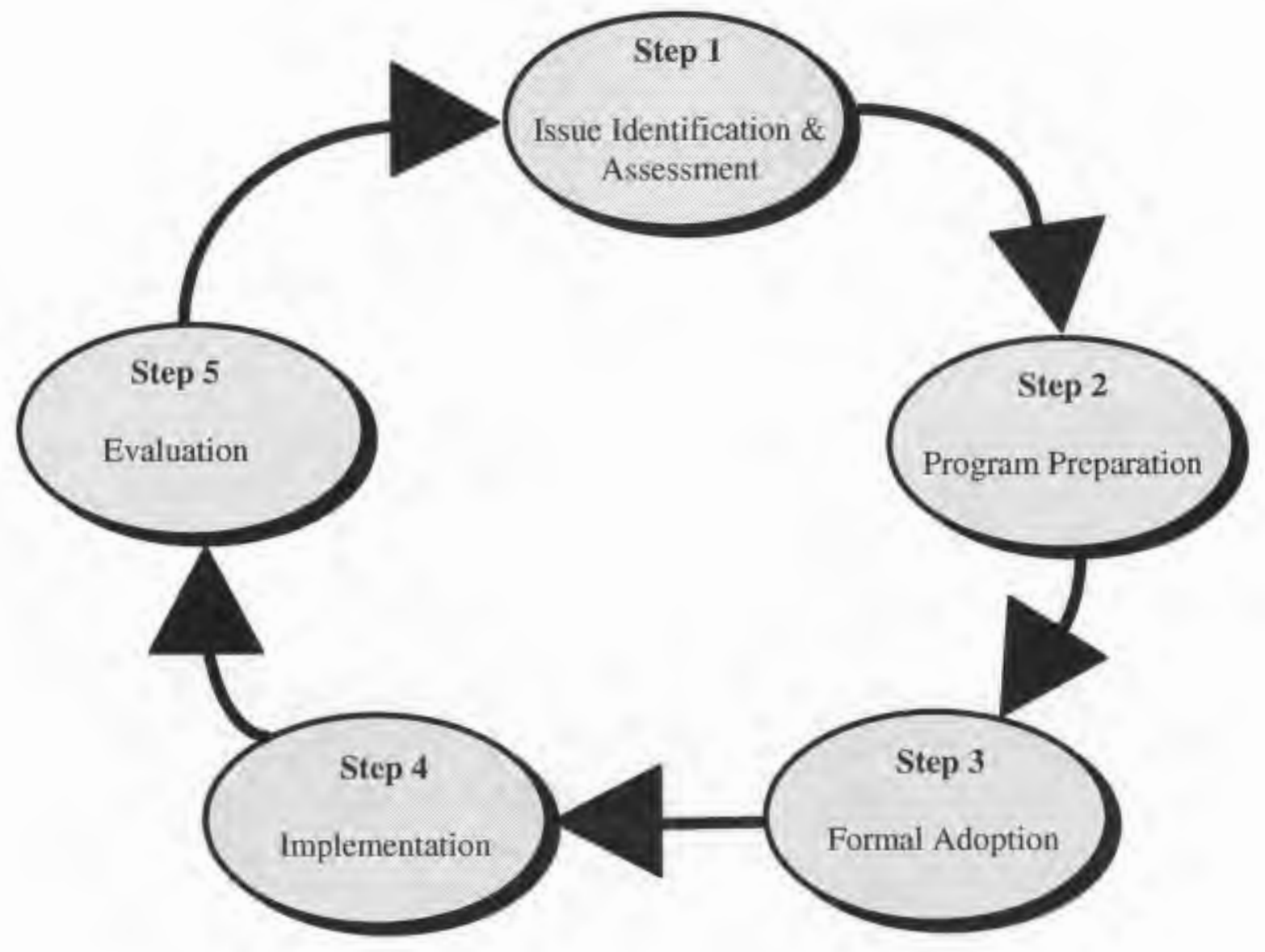


Strategic Decision Making

In order for ICM to be successful, it must make a series of strategic decisions that will influence how the process is carried out. These decisions must define: the geographic scale of the planning process, what issues should be addressed by the project, who the key actors and institutions are for ICM and how to make the most on-the-ground progress within the time and resource limitations of the project. Over the life of the project and throughout the entire process, strategic decisions are made on a regular basis by the planners and key decision makers. ICM also strives to ensure that these decisions are made after significant consultation with key stakeholders.

\section{Comparing ICM and Contemporary/Strategic Planning}

There are clear similarities between ICM and contemporary/strategic planning. These can be best described by re-creating the table used by Kaiser and Godschalk $(1995,381)$ with one modification that adds another column for ICM so that it can be compared with attributes of hybrid plans (Table 1). The revised table also includes three new attributes: focus on process, innovation, and role of the planner. These are drawn from Innes' article and were added to tighten the link between Kaiser and Godschalk's hybrid plans and Innes' planning by consensus model. As previously discussed, both methods share the same attributes and fall under the umbrella of comprehensive planning.

This comparison between ICM and hybrid plans shows that there are significant similarities. Based on the experience provided by the case study, the most prominent features that are shared include: focus on implementation and issue-driven action, strong public participation, strategic decision making and an emphasis on planning as a process. 
Similarly, these attributes are also shared by strategic planning approach described by Bryson (1988). These clear commonalties demonstrate that ICM fits within the new view of comprehensive planning as described by Kaiser and Godschalk and Innes and it includes many of the key features of strategic planning. In fact, ICM may be an ideal example of the blending of these two approaches and demonstrating the intertwined approach to contemporary/strategic planning.

TABLE 1 - COMPARISON OF PLAN TyPES AND ICM

(modified from Kaiser and Godschalk, 1995)

\begin{tabular}{l|l|l} 
Attributes/Features & 1990s Hybrid Plans & ICM \\
\hline \begin{tabular}{l|l} 
Land Use Maps \\
Nature of
\end{tabular} & General and area specific & As necessary \\
Recommendations & Policy and actions & Policy and actions \\
Time Horizon & Short and Long term & Short and long term \\
Link to Implementation & Moderate to Strong & Strong \\
Public Participation & Active & Active \\
Land Use Linkage & Strong & Issue-dependent \\
Environmental Protection & Strong & Strong \\
Social Policy Linkage & Moderate & Strong \\
Focus on process & Moderate-strong & Strong \\
Role of the Planner & Facilitator/Convener & Facilitator/Convener \\
Innovation & High & High
\end{tabular}

The most significant difference between ICM and contemporary/strategic planning is the use of land use maps. ICM uses the land use map as one of several management tools, applied as needed based on the situation. Land use maps are at the core of contemporary/strategic planning and are generally the focus of the planning process.

The next chapter provides a case study about an ICM project in East Africa which demonstrates two key attributes of ICM and contemporary/strategic planning - strategic 
decision making and viewing planning as a process. The case study highlights the strategic decisions that were made during the project which contributed to its success. It then focuses on each of the policy process steps and how they were completed in a compressed time frame. Finally, this chapter looks at the methods used throughout the intervention to complete the policy process quickly and build capacity for ICM. 


\section{EAST AFRICA PILOT PROJECT CASE STUDY}

The chapter begins with an overview of the project design, how it was developed and managed during its two year implementation. It discusses the project's goals, management organization and implementation schedule. Each pilot sites' geographic scope and the range of ICM issues that where addressed by the project are also discussed.

\section{Country Context}

Eastern African Nations-Somalia, Kenya, United Republic of Tanzania, Mozambique, Madagascar, Mauritius, Seychelles, Reunion and Comoros-recognize the significance of coastal resources and regions to their national development. However, translating the goal of coastal management into meaningful, tangible and practically achievable actions remains elusive. Throughout Eastern Africa the resource base is being degraded at an ever-accelerating rate, causing economic hardship to the millions of residents whose livelihoods are directly dependent upon these resources, loss of substantial national development opportunities, and undocumented, but significant losses in biodiversity (The World Bank 1996; Webster 1994; SAREC __ ).

In 1985, Eastern African nations came together under the auspices of the UNEP to sign the Eastern African Regional Seas Action Plan and a number of protocols to promote regional cooperation to better manage the marine and coastal environment. Over the last decade, a number of UNEP activities have been carried out to enhance principally the technical basis for coastal management. In 1993, ministers from throughout Eastern Africa convened in Arusha, United Republic of Tanzania, and signed a resolution stating their commitment to sustainable coastal ecosystem development and management. In 
1996, a second Ministerial meeting was held in Seychelles where the East African nations re-confirmed their commitment to coastal management. Complementing these high-level calls for coastal management has been an increasing interest and a few local-level projects to address some widely recognized coastal problems. For example, IUCN and Irish Aid have a significant effort underway in the Tanga region of Tanzania which appears to be yielding significant results.

\section{Project Description}

To build upon the region's momentum and to make progress in resolving specific issues in critical areas of East Africa, UNEP, USAID REDSO-ESA and the University of Rhode Island CRC designed a small-scale coastal management project - The East Africa ICM Pilot Project - in 1993. The one-year project was designed to initiate the ICM process in two pilot sites by identifying critical issues and making some incremental progress on resolving some of those issues. It was not designed to resolve or even address all the coastal issues facing the people in the pilot site, but to introduce ICM to the appropriate institutions in each place, build teams of technical experts capable of guiding the ICM process into the future and begin developing the necessary local and national constituency for ICM implementation. The resources available to the project, in comparison to other ICM development projects, were extremely modest. The first year's funding from USAID totaled \$120,000 US to operate both pilot sites. An extension and second year funding was provided at a level of $\$ 60,000$ from USAID. In addition to this core funding, UNEP provided approximately $\$ 30,000$ to each team during the life of the project. Other ICM development projects designed to initiate ICM in a country generally operate on funding levels in the range of $\$ 300,000$ to $\$ 700,000$ per year. 
Project Goals and Objectives

The goals from the project's proposal include:

1. Demonstrate how to formulate effective, participatory approaches and strategies for addressing representative coastal management problems in the Eastern African Region.

2. Begin to build the local, national and donor support required for implementation of the CRM strategies at two pilot sites.

3. Promote regional learning about coastal management and information exchange among coastal management practitioners.

To achieve the goals within the time and resources available, the following strategies were applied:

- Focus project activities in two sites-Mombasa/Bamburi, Kenya and Unguja Island, Zanzibar, United Republic of Tanzania-so that some tangible progress in addressing coastal problems could be made. These sites were selected based both on the salience of the issues to the rest of the region and the existing institutional capabilities to make progress within the project's framework.

- Use a collaborative technical assistance style and adult learning approach to convey the critical actions and participatory process required by each step of the ICM policy cycle in order to accelerate progress and maximize capacity building within each national demonstration site. 
- Conduct a regional workshop for coastal management practitioners to facilitate the exchange of ideas and information within East Africa.

From the earliest stages of the project, it was hoped that this initial ICM work would lead to more intensive country-specific follow-on activities that fund implementation of project-developed strategies through USAID or other donor assistance.

The original design was for a one year intervention in both Kenya and Zanzibar. By the end of the project there had been nine missions spanning from October 1994 to November 1996. Each mission's objectives and expected outputs were developed by CRC in cooperation with the team leaders and the UNEP and FAO representative assigned to the project. Mission dates and objectives are summarized below (Table 2). The modest resources needed for the project's second year were provided by USAID/REDSO-ESA. The additional investment was made to ensure that the teams had adequate time to complete the project's goals as designed. Each team had completed all the project's proposed goals by March of 1996, taking only 17 months to complete a first iteration of the ICM process. 
TABLE 2 - SUMmaRY OF ACTIVITIES

\begin{tabular}{|c|c|c|c|}
\hline Year & Month & $\begin{array}{l}\text { Weeks in- } \\
\text { region }\end{array}$ & Step in the Policy Process \\
\hline \multirow[t]{2}{*}{1994} & June & $\begin{array}{l}\text { four week } \\
\text { course at } \\
\text { URI }\end{array}$ & Capacity building- Team leaders attend short course in ICM. \\
\hline & October & four & Issue Identification \\
\hline \multirow[t]{5}{*}{1995} & March & four & $\begin{array}{l}\text { Issue Identification } \\
\text { Strategy Development }\end{array}$ \\
\hline & June & four & Stakeholder Feedback on Issues and Strategy \\
\hline & July & $\begin{array}{l}\text { two } \\
\text { weeks in } \\
\text { US }\end{array}$ & $\begin{array}{l}\text { Capacity Building - Team leaders attending international } \\
\text { workshop on coastal management in Florida. }\end{array}$ \\
\hline & September & four & Prepare each team for national workshop \\
\hline & December & one & Formal adoption of strategy in Kenya \\
\hline \multirow[t]{4}{*}{1996} & January & three & $\begin{array}{l}\text { Implementation of strategy; formation of Coastal Resources } \\
\text { Steering Committee (CMSC) in Kenya }\end{array}$ \\
\hline & March & three & Formal adoption of strategy in Zanzibar \\
\hline & August & one & Implementation activities begin in Kenya \\
\hline & October & $\begin{array}{l}\text { two/Kenya } \\
\text { Only }\end{array}$ & CMSC's completes first implementation activity in Kenya. \\
\hline
\end{tabular}

The project officially completed its original contractual obligations at the conclusion of each national workshop and distribution of the final document. In Zanzibar, the technical missions stopped because of a change in government after Zanzibar's March 1995 elections. In reaction to this change, many of the international donors ceased all assistance activities Zanzibar. One of these donors had committed to a multi-year followup coastal management project that would have implemented the strategy document created by the team and expanded the scope of ICM within Zanzibar. Today in Zanzibar, the team is working slowly on distributing the strategy document and organizing the institutional structure called for in that document without external assistance.

Work continues in Kenya. The team is now the secretariat to the Coastal Management Steering Committee (CMSC) which was formed at the ICM national workshop in 1995 and given the responsibility for implementing the ICM strategy. The team has secured 
several small grants that will allow them to continue making progress at the pilot level. The CMSC is also actively seeking a donor capable of making a significant investment in ICM to fully implement the strategy document. USAID has continued its commitment to ICM in Kenya by providing modest funding to the CMSC. This funding allows the CMSC to meet on a regular basis and complete small-scale implementation activities.

\section{The Pilot Sites: Initiating Integrated Coastal Management in East Africa}

\section{Zanzibar}

Zanzibar is composed of two main islands, Unguja and Pemba, and 53 islets, which united_with Tanganyika (it gained its independence from the UK in December 1963) in 1964, creating the United Federation of Tanzania. However, under its Union Constitution, Zanzibar maintains an autonomous government (only foreign affairs, defense and higher education are Union matters). Unguja, or Zanzibar Island, is principally a coralline-based island, located 22 miles off the Tanzanian mainland. Most of its estimated 745,000 inhabitants have some dependency on the coastal region (Zanzibar Integrated Coastal Management Team 1995).

Traditional coastal dependent economic sectors include fishing, seaweed farming and mangrove forestry. Resources utilized by these activities are in relatively good condition (Zanzibar Integrated Coastal Management Team 1995). The only traditional economic sector that is not coastal dependent is agriculture (clove/spice growing) which has recently "crashed." The burgeoning economic activity is coastal tourism. The Zanzibar government is promoting this activity with vigor by using the excellent state of the natural resources base and its fascinating cultural history as the primary marketing point. Zanzibar, because of the relatively unspoiled resource base is in a competitive position to 
draw tourists from other destination areas on the African east coast, such as Mombasa, Kenya.

\section{The Major ICM Issues}

Coastal issues in Zanzibar are being intensified by the rapid increase in coastal development. New hotel developments are creating new pressures on the resources, impacting the local culture and disrupting traditional use patterns. The following is a preliminary list of the primary issues identified by the planning team during the issue identification step in the process.

Mitigating environmental and social impacts from tourism. Tourism in the study site and throughout the island is rapidly expanding, increasing concerns about the related social and environmental impacts. New hotel development is happening in close proximity to traditional villages adding to the pressures created by the few existing hotels. Current impacts include space/user conflicts between hoteliers and villages, increased pollution, and encroachment on existing social patterns. Currently, shorefront development is only marginally controlled and there is no consensus on tourism policy and land development schemes.

Sustaining and enhancing artisanal fisheries and seaweed farming. There is a high degree of dependence on artisanal fisheries and seaweed farming by the villages. Both activities are under increased pressure from expanding development. Fish habitats and water quality are threatened by pollution from development and competition between villages and hoteliers for shorefront space is increasing (Zanzibar Integrated Coastal Management Team 1995). The use of shorefront land is an especially potent issue between hoteliers and seaweed farmers. 
Maintaining mangroves and coastal thickets for sustainable harvest, fisheries and nature conservation.- Mangrove forests and surrounding ecosystems play a vital role in the economic and environmental well being of Zanzibar. Mangroves are utilized by the community for construction and fire wood, food collection and beekeeping. These systems, which are presently in satisfactory condition, are threatened by overcutting and pollution.

\section{The Pilot Site}

The demonstration site selected by the team is an area located on the Southeast side of Unguja Island approximately $20 \mathrm{~km}$ from Zanzibar town. The Zone is delineated by a line:

starting $1.5 \mathrm{~km}$ north of Uroa to where the tourism zone ends, $1 \mathrm{~km}$ inland extending to the end of the southern end of the tourism zone. This line joins with an east-west section line that runs along the parallel latitude $6^{\circ} 13^{\prime}$ to a road that leads to Ukongoroni village up to grid 13 to a point $1 \mathrm{~km}$ from coasts. The boundary then turns south to $2 \mathrm{~km}$ south of Paje which is the terminus of the tourist zone. The Michavi peninsula is included in its entirety. Offshore the boundary is drawn $1 \mathrm{~km}$ seaward of reef crest, including the offshore reef patch between Ras Uroa and Ras Michavi (Map A). 
Map A - Zanzibar pilot site

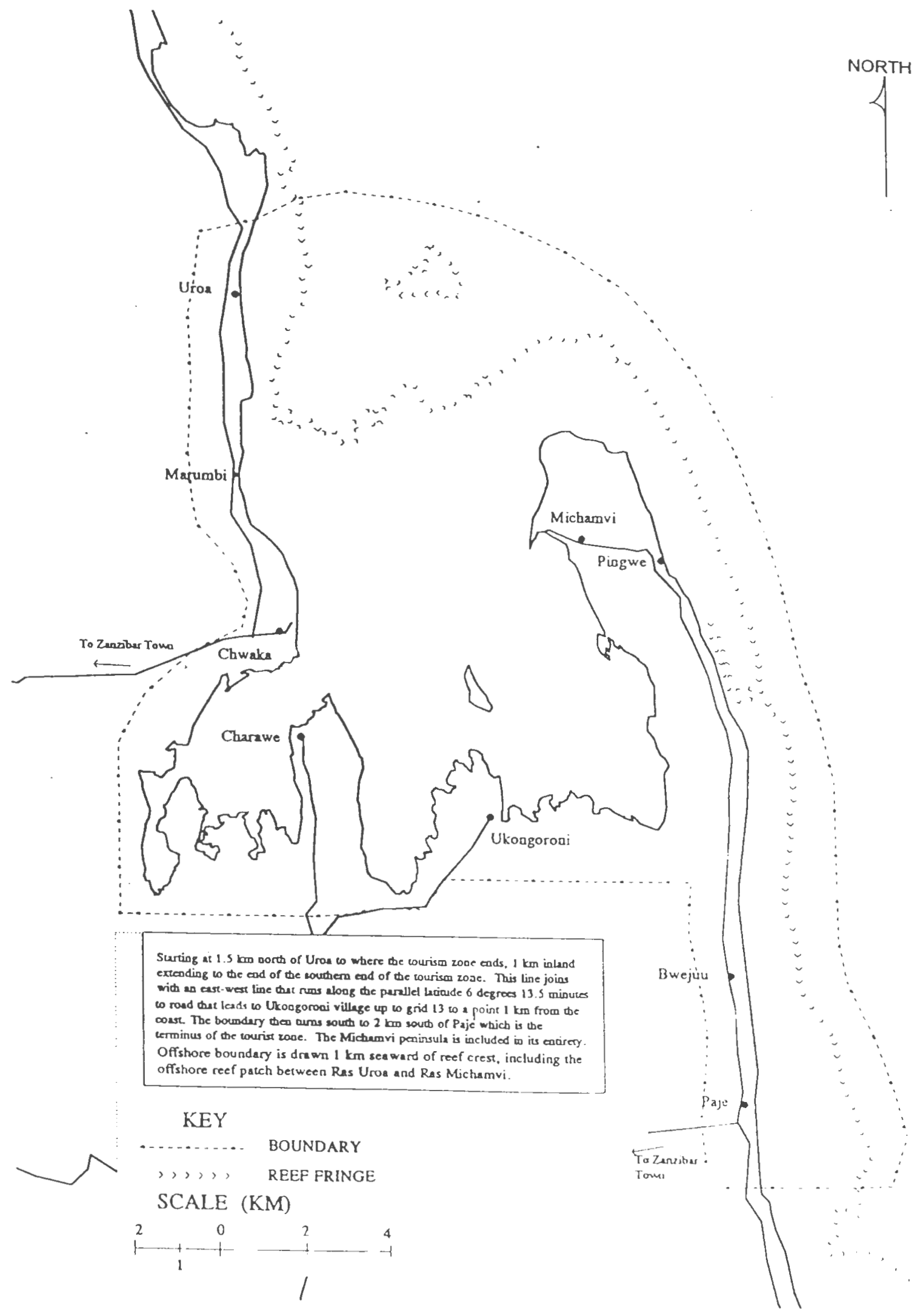


This site contains rural fishing communities that enjoy good environmental quality and resource condition. In addition to the artisanal fishing, village activities include seaweed farming, mangrove pole harvesting, beekeeping, reef gleaning, coral collection, and rope making. Throughout the demonstration site tourism development is expanding rapidly. The focus of the ICM activities in the site will be to prevent inappropriate development and maintain the quality of the environment and sustainability of the resource base upon which the coastal communities are highly dependent.

Kenya

Kenya faces many of the same problems of many nations with respect to its developing economy, as well as environmental and resource management issues along the coast. The predominant economic activity is coastal tourism. Approximately 60 percent of tourism in Kenya occurs along the coast (Kenya Integrated Coastal Management Team 1995). Tourism is the leading foreign exchange earner for the country, surpassing tea and coffee, and depends heavily on the quality of the resources and environment to attract tourists and compete effectively in an increasingly competitive world market. In addition to its importance to tourism, the coast is also an important center for national and regional trade, particularly through the port of Mombasa. The coast has a long and illustrious history as an important trade route, with cultural traditions and influences from European powers and the Islamic Arabs.

Important coastal resources provide food in terms of fish and construction materials from mangrove forests, as well as significant employment. Kenya also has one of the largest marine parks and marine reserves program covering approximately 20 percent of the total country's coastline. While most of the population, estimated in 1993 to be approximately 
$27,700,700$, lives in the interior portions of the country, the narrow coastal divisions are heavily populated (Johnson et al. 1994, 213). A relatively high population growth rate of 3.7\% (Johnson et al. 1994, 213) is exacerbating expanding migration from the interior to the coast. This is particularly evident in the Mombasa District where population increases constantly outstrip the ability of the local government to provide general services, such as housing, potable water, waste disposal, education, and telecommunications. The coastal region is also viewed as one of the few areas of the country where significant opportunities for agricultural expansion exist.

Kenya has a strong human resource base of trained personnel and marine scientists along with a strong institutional web of government agencies with jurisdiction and authority in the coastal zone. There also is a relatively good information base on trends in the condition and use of coastal resources and associated problems of management.

\section{The Major Issues}

Kenya's coast contains many of the general development problems faced in the rest of the nation. These range from inadequate food and water supply to lack of housing and employment. Other critical issues include poor health facilities and high incidence of various diseases, lack of sewage systems and low education and literacy (UNEP 1984).

Problems specific to coastal areas have been document in two coastal profiles by Kenya Integrated Coastal Management Team (1995) and Constandinides (1993). The critical coastal issues include:

- Overexploitation of marine resources, particularly of fisheries and mangrove forests. 
- Coastal erosion and inappropriate siting of shorefront development.

- Poor land use management contributing to coastal urban sprawl.

- Use conflicts (e.g., tourism and fishing).

- Impacts from tourism development (e.g., pollution, use and cultural conflicts).

- Reef degradation from destructive fishing and tourism recreation.

- Siltation in estuarine areas and proximate coral reef environments.

\section{The Pilot Site}

The project site was originally designated as the Bamburi area of the Mombasa District, defined through previous work initiated under the UNEP EAF/5 Project. This initial area is a coastal strip of tourist hotels located adjacent to the Mombasa Marine Park and Reserve. After much discussion and several field visits to the area, the project team decided to expand the project to be more representative of national coastal management issues. The expanded boundary incorporates both the urbanizing area of Bamburi as well as a mangrove and estuarine area more rural in character. The team also felt that the expanded area was more politically salient to the both government and private sector stakeholder groups, which would eventually aide in obtaining endorsement at the local and national levels for the strategy document.

The project area falls entirely within one administrative district, Mombasa, located within the Coastal Province of the nation of Kenya (Map B). It is bounded to the north by Mtwapa Creek and to the east by the limits of the outer coral reef fringe, approximately one to two kilometers offshore. This encompasses only the part of the Mombasa Marine Park and Reserve areas where use is intensifying, conflicts increasing and threats to environmental quality the greatest. 
Map B - Kenya Pilot Site

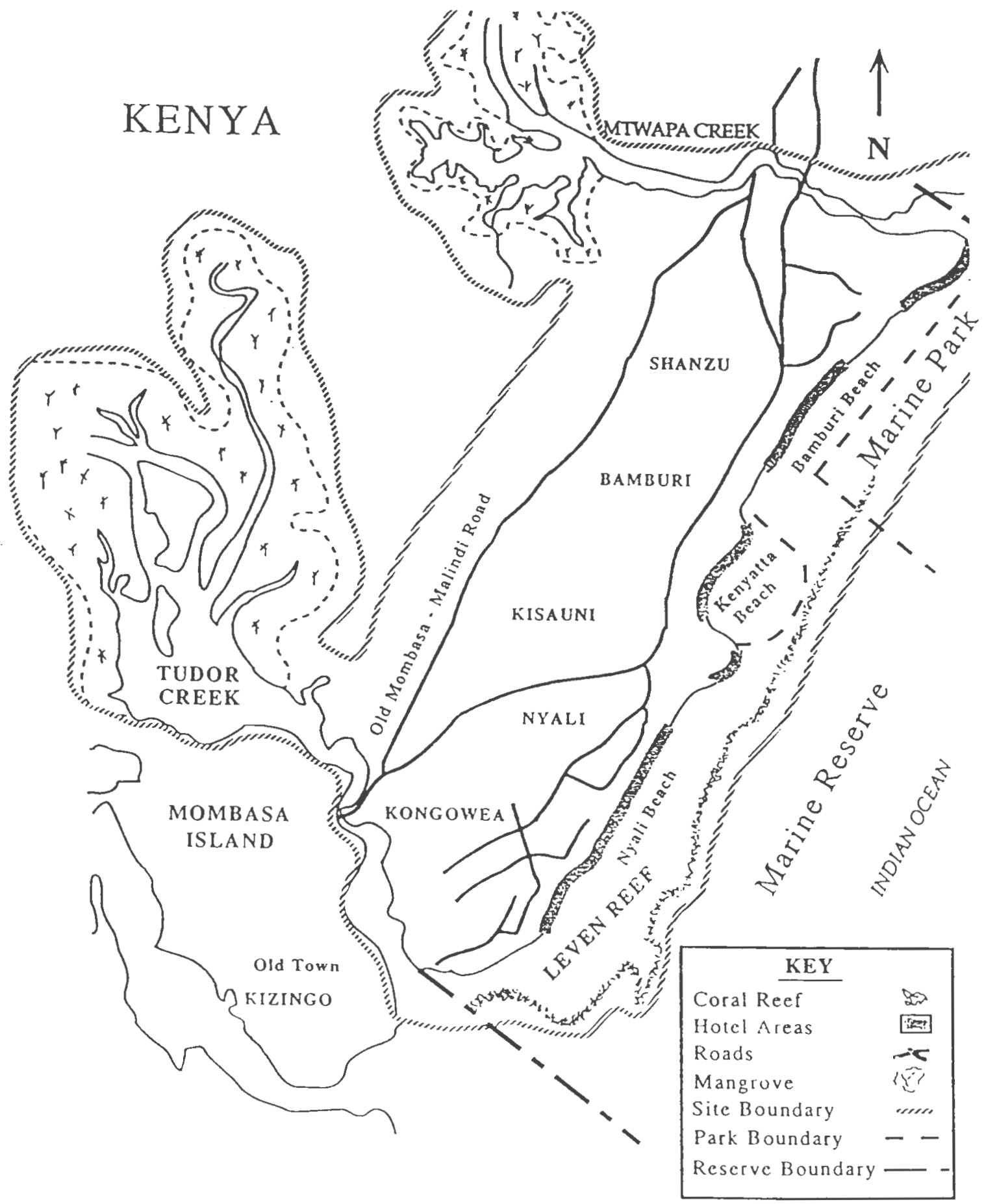




\section{THE PROCESS AND TECHNIQUES USED IN THE EAST AFRICA PILOT PROJECT}

Two key attributes will be explored by this case study: strategic decision making and the use of the ICM policy process by the project. Both of these are key attributes of ICM and contemporary/strategic planning and served as the foundation for the success of the East Africa ICM project. This chapter also highlights the intervention techniques used during the project.

\section{Strategic Decision Making}

To build a framework that can guide significant investment in coastal management projects and facilitate immediate change on the ground with the available resources, the project had to focus heavily on making the appropriate strategic decisions so that the project would address immediate problems while looking forward into the future to solve future problems. This section highlights those strategic decisions. By making strategic decisions, the team was able to attain quick results on addressing the most critical and realistic issues as defined by the local stakeholders while developing a foundation for future ICM activities and programs.

The process used in the East Africa pilot project is based on the ICM planning process and follows the same steps that would be used in developing a national ICM program as outlined by Olsen et al (1996). However, the time taken to complete the steps was significantly compressed and the scope of the issues the process addressed focused on the problems of the pilot site. This was accomplished by strategic decision making on the following points: 
- selecting a pilot site to test ICM and strategically selecting the issues to be addressed,

- linking the local level activities to a national levels of government,

- selecting a agency to lead the process,

- building an interagency team to complete the work, and

- identifying and working on the appropriate issues.

Decisions on each of these points were made after considering the resources available to the project, the project's limited timeframe, the existing capacity (both human and institutional) within each pilot site, and the need to initiate ICM successfully. Making the correct decisions was critical to the success of the project. By the end of the process as a result of the strategic decisions, the team has created a strategy document that facilitates progress on critical issues that are within the team's existing capacity to solve and sets forth a framework to direct future investment. This decision-making process also provided ample opportunity for the ICM teams to learn about the ICM process and barriers to making progress on developing and ICM Program. It is anticipated that this experience will provide critical insights as the ICM process is extended from the pilot site to the regional and national level.

\section{Pilot Site Selection}

One of the earliest strategic decisions that the team made involved selecting the pilot sites. The site had to be of adequate size to express a sampling of national ICM issues but small enough to be manageable by this project. It had to be accessible to the team and include a range of stakeholders that would be willing and able to participate. Both teams originally suggested sites that were large and complicated. Because of the project's 
limited resources and subsequent design, it was critical that the pilot's size be manageable. The team, on the other hand, wanted to address a range of issues within a large geographic area that they felt were most important to the country. After a significant amount of input from the technical advisors, both teams eventually selected pilot sites that were manageable and did represent a selection of issues that had national salience.

\section{Linking Local and National Levels of Government}

Before proceeding the teams had to consider how to link the local and national levels of government. Any coastal management effort must create links between national and local levels of government (GESAMP). This "two track" approach, pioneered by CRC, is critical for resolving complicated, multi-jurisdictional resource management issues. Building the bridge between the two governance tracks was initiated early in the project.

In Zanzibar, the team held an informal meeting for all the sectoral agency directors. Also, because of the Zanzibar team leader's senior position, briefings could easily be given to key Ministers and Permanent Secretaries. In Kenya, the challenge was greater. Kenya's government system is larger then that of Zanzibar's. Also, the Kenya team lacked a senior government official, making it very difficult to reach into high levels of government. Complicating this situation, the Kenya system of resource management is very sectoral and emphasizes national decision making. This created significant impediments to the team's efforts to link different government institutions and different levels of government. After much discussion, the Kenya team decided not to link the pilot site activities with the Ministerial level of national government. Instead, they would keep national government informed through papers, reports and briefings, and instead involve agency directors as the upper track in the two track approach. 
Lead Agency Selection

Another strategic decision made very early in the project was the selection of the lead agency. Selection of the lead agencies was done by USAID, UNEP and CRC before the project began in-country activities. Originally, the lead institutions were going to be the research organizations in each place. The research organizations were the normal partner for UNEP's EAF/5 project and they often had better capacity (human and resources) then government management agencies to initiate ICM. However, after considering the importance of having an institution that has management authority to implement ICM, the Coastal Development Authority in Kenya (CDA) and Department of Environment in Zanzibar (DOE) where chosen. Both these agencies have responsibility for managing coastal areas. CDA's management is focused on developing the economy of the coastal region of Kenya. DOE is the primary agency responsible for environmental management for all of Zanzibar.

\section{Building ICM teams}

At the heart of the project were the multi-agency, multi-disciplined ICM teams. They were created before the in-country missions began by the team leaders. The team leaders represented the project's lead institution. In Kenya, the lead institution was the CDA and the team leader was CDA's operations manager. In Zanzibar, the team leader was the Director of the DOE. Both team leaders had excellent educational backgrounds. The Kenya team leader received his doctorate in Animal Husbandry from Texas A\&M University and the Zanzibar team leader has a planning degree from Oxford University, but neither had working experience in the ICM field. 
The team leaders organized their team with little input from CRC, except for the request that the team members come from institutions relevant to managing coastal resources, such as the departments of fisheries, forestry, and land planning. The only other parameter for team member selection was that the candidates had to be able to dedicate a significant amount of time and effort to the project.

The Kenya team consisted of thirteen members from CDA, Mombasa Municipal Council, Kenya Wildlife Service, Fisheries Department, Kenya Association of Hotel Keepers and Caterers and the Kenya Marine Fisheries Research Institute. In Zanzibar, the team was made up of nine members from DOE, the Institute for Marine Science, Department of Fisheries, Department of Forestry and the Integrated Planning Unit of the Commission for Lands and Environment.

Both teams were made of mid-level staff members representing their agencies. They were individually responsible for informing their directors about the progress being made and ensuring that their organization was supporting the overall effort. The team leader and the team members had the power to make decisions such as what the final set of ICM issues were, when and which stakeholders should participate, and how higher levels of government should be informed. The team also had the final responsibility for writing the strategy document and, therefore, fully influenced what it would contain. CRC provided technical assistance to the team on how to move through the process and advised on the many decisions that had to be made, but the final decision making authority rested with the teams.

Another element of team building was finding a mechanism to ensure consistent participation by the team members. This is often done by development projects by providing monetary compensation to the team members in addition to their government 
salary. Because of USAID regulations, the project was not able to "top off" government salaries with USAID funding. This posed a potentially significant impediment to progress; although the teams were willing to work without this topping up of salary, their off-work hours had to be spent earning additional income to support themselves and their families instead of working on the ICM project. This situation is not uncommon in developing countries where government salaries are below what is needed to maintain a household. Therefore, government workers are forced to take second jobs to provide supplemental income. To alleviate this situation and to ensure that the team members could focus on the ICM project, honorariums where provided using funding from UNEP and the USAID funding was directed towards operational expenses only. Providing these modest honorariums proved to be critical to the success of the project.

Throughout the process, the ICM teams had to strategically identify, focus and refocus the issues and proposed strategies. It was critical that the teams focused on issues that could be addressed within the parameters (human and financial resources) of the project, while giving all the issues identified by the stakeholders the appropriate level of attention. This focusing and refocusing was done through a participatory, consensus building process similar to the approach used by Innes (1996). The ICM teams worked with the stakeholders to "discover" the public interest and develop innovative solutions. The team served as both technical experts and facilitators and conveners. By continually thinking strategically about the scope and structure of the process, the team was able to make progress on ICM issues without being overwhelmed or stretched beyond their limited capacity. 


\section{ICM Process}

The same process developed by CRC that is applied in larger, long term ICM interventions was used, in modified form, by this project. However, the process's outcome was not to establish national and sub-national ICM program for the country, which experience shows takes up to fifteen years to complete (Olsen et al. 1996). Instead the process's outcome was to complete a strategy that would initiate ICM in the country. Therefore, the abbreviated process, containing the same steps, can be viewed as an "eddy" of the main process flow (Figure 2). The hope and expectation is that the team will continue to follow the policy process while working at increasingly high levels of government. With each step towards national ICM, the time and effort to complete the process increases.

The project was designed to take the ICM teams through each step of the policy cycle in a very short period of time, instead of several years for each step, which is the norm when developing a national ICM program (Olsen et al. 1996). Once this "experiment" was completed, the ICM teams had a basic strategy which serves as the foundation for a future coastal management program. By following the process steps, the teams were able to experiment with the activities included in each step and learn about the barriers to completing each step in their pilot site. These lessons will be invaluable when a national or sub-national ICM program is developed.

Other important attributes of ICM were also incorporated into the process. Within each step, actions that supported and encouraged key attributes such as ensuring participation, building capacity and linking local and national levels of government were included. These actions matched the scope and scale of the project; they focused on the pilot site and did not attempt to achieve more then was possible. By completing these actions, the 
team learned valuable lessons, such as how to achieve appropriate levels of participation, how to inform and include government leaders in the process and how to raise public awareness about critical coastal issues.

The experience of the ICM teams as they moved through each of the five steps in the policy process is described below. 


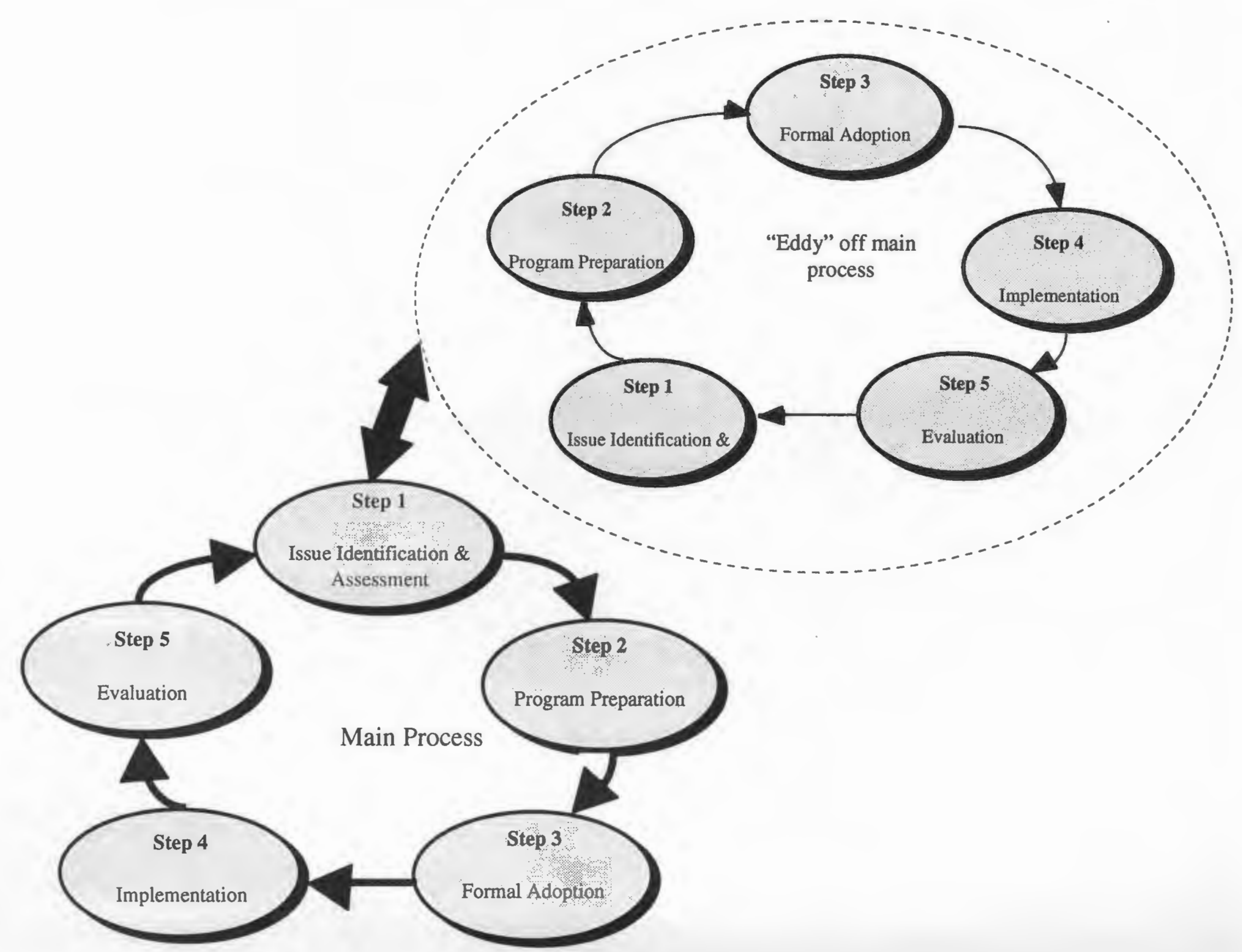


Issue Identification

The first step in the process was to develop a consensus of the pressing ICM issues, supported by the best available information. To achieve this within the project's timeframe the teams were taught how to rapidly collect field data. After the classroom training the teams went into the field to collect data for the strategy document. In addition to collecting useful information, this exercise began the team building process. For issues that lacked any significant body of information, local experts were commissioned to conduct research to collect the necessary information. This information would not be used in developing the strategy but once collected, would help guide management decisions.

One of the data collection techniques used in the field was the Rapid Rural Appraisal (RRA) technique (Pollnac et al. 1994). Once the technique was taught, the teams developed the necessary data collection tools such as interviews, mapping and secondary data collection from records maintained by the sectoral institutions. The teams then used these data collection tools to identify key stakeholders, possible ICM issues and solutions.

Once the data were collected, the teams applied a cause-consequence analysis for describing the issue (Olsen and Hale 1994). This method systematically takes the issue and considers it in terms of the causes of the issue and the consequences. This two-step process helped the team develop clear descriptions about the coastal problems and their consequences. The teams used the information about the problem's causes to develop the actions and planning strategies. This helped the team focus on the actual causes of the problem, not the symptoms. 
The rapid assessment of the issues combined with input based on the team's perception of the problems formed the initial issue statements. In Kenya, the team wanted to address issues that had to be continually balanced against the project's capabilities and resources. For instance, water supply in coastal Kenya is a significant issue for the coastal population. The local water supply, from wells, has been contaminated with domestic sewage and the upland sources of water are being consumed by the tourist hotels. Clearly, this was an important issue that needed to be addressed. However, the team with their existing resources could not have resolved this issue. Instead, the team clearly stated in the strategy document that this was an issue that required future attention and selected several of the causal factors they could solve, such as excessive water use by hotels, and incorporated those into the immediate action section of the strategy document.

\section{Strategy development}

Using the selected issues as the foundation, the team then described their vision for the pilot site by defining the strategy's goals and objectives. The goals and objectives were "leveled" into a hierarchical order. The goals described how the place should be in the future. The objectives were discrete actions that were bounded by either short or long term time frames. The objectives were used to select the appropriate strategies for solving the problems.

The strategies were divided into two general categories: planning and action. The planning category was used to compile the longer term activities, including future planning. For example, to address the drinking water contamination problem in Kenya a working sewer system needs to be installed in the densely populated neighborhoods in 
Bamburi. The strategy developed to address this effectively was to commission a waste water treatment plan at some time in the future. The second category was for near-term actions that would directly address and make progress on solving an identified problem. These actions were developed with the understanding that serious problems exist that need immediate attention. These are the "stop gap" measures that will address immediate concerns while the planning process goes forward to find the best long term solutions. The near-term action to address the water issue called for a water conservation program implemented by the hotels that will reduce the amount of piped water used by the hotels and increase the amount available to the community, thereby reducing their reliance on contaminated well water. The planning category also provides a framework that can be used to guide donor aid coming into the country or to solicit funding for particular activities.

As the teams developed the action strategies, they considered a collection of standard regulatory and non-regulatory management tools used for ICM globally. Because both countries' resource management regimes heavily the regulatory approach, many of the teams' proposed actions were regulatory solutions. But because there is no official mandate or enabling legislation for ICM the teams had to either revise existing laws or use non-regulatory tools. Therefore, non-regulatory tools such as education, community activism and involvement comprise most of the short term action strategies.

Participation by local stakeholders was an important attribute of this step in the process and in the overall project. Stakeholders were defined as any person who has an interest in the pilot site, the issues related to the pilot site or someone who had a role in resolving the pilot site's issues. The teams used this broad definition to identify who would participate in the process in terms of groups and individuals. When the team was unsure which individual should be invited to attend a stakeholder meeting they would contact a 
key informant, such as a village elder, for recommendations. The teams created an opportunity for participation at two levels. The first was attending public meetings to provide input to the strategy. These meetings brought together a wide range of stakeholders that extended from local fisherman to naval officers. The second level of stakeholder participation was key informants and advisors. These people, although not on the ICM team, influenced the direction of the project by providing direct input to the teams on a regular basis. They generally represented stakeholder groups, such as researchers, fisherfolk, and boat operators.

The issues and their causes and consequences developed by the ICM teams were reviewed by the stakeholders at a series of stakeholder meetings designed to facilitate two-way communication. The ICM teams informed the stakeholders about the planning process, and sought their input and suggestions on the team's initial findings. The stakeholders gave the ICM team critical information about the pilot sites and proposed actions for resolving the problems. The stakeholder meetings also served as an important step in raising awareness about resource management and creating connections between stakeholders and the governing institutions.

The workshops in Kenya and Zanzibar were organized differently, each tailored to the site's specific needs. The Kenya team conducted a two day workshop with a large number of participants. The workshop was interactive, allowing workshop participants to review an rework the issues and propose actions. The Zanzibar team conducted a series of smaller workshops because it was impossible to get all the stakeholders from the pilot site together in one area. Village meetings were conducted in the local language and both genders were equally represented. However, it became necessary to separate the two gender groups because of cultural norms. The Zanzibar team also conducted two workshops for a single group of key stakeholders. These included the hoteliers, who 
have a significant amount of influence on how, when and where the coastal resources will be developed and the directors of key government agencies.

The teams used the input from these workshops to develop a final draft of the strategy document. The final draft was based on the data collected in the early missions, revised by the stakeholders and finalized by the teams. The documents present findings of fact about the critical coastal issues based on the available secondary data and the primary data collected by the team. For each issue, strategies are presented. These are sorted by implementation and planning actions arrayed under goals and objectives. The final chapter of the strategy document outlines the proposed institutional structure to implement those actions.

Adoption

Both teams developed an institutional structure for implementing the strategy document. The proposed structure was reviewed by key agencies and local officials and was presented at a national workshop. Here the teams sought approval of the proposed institutional structure by workshop's participants. Both teams were successful in getting the structure adopted. The workshops also provided a final opportunity for stakeholders to comment on the strategy document. Both workshops were conducted using participatory methods. Small groups worked on different chapters in the document and provided their comments and suggestions to the workshop delegation. In Zanzibar, all the participants were provided an opportunity to comment on any proposed changes to the strategy document during the plenary, and votes were taken on every change suggested. In Kenya, the team revised the document in the months following the national workshop. Stakeholder contribution created strong support for the final document and the proposed institutional structure to implement the document. 
After completing this step in the policy process, the teams did not have a final comprehensive coastal resource management plan, but a strategic look at the coastal management issues and a strategy for making progress on resolving these issues over the short and long terms. These strategy documents were developed to serve as maps for guiding future investment as well as workplans to guide the implementation of immediate actions. The development of the strategies also contributed to the process of constituency building and awareness raising for ICM.

The first step towards implementation after the national workshop was to establish the institutional structure endorsed by the workshop participants. In Kenya this structure was a intersectoral committee of agency directors and representatives of local user groups, such as fisherfolk and boat operators, called the Coastal Management Steering Committee (CMSC). The first act completed by the CMSC was to adopt the strategy document. The CMSC does not have officially sanctioned responsibility to manage the pilot's resources. Instead they serve as an advisory board that will guide the implementation of the strategy document. This will be achieved by coordinating subcommittees and incorporating recommendations from the strategy into their institutions' workplans. A sub-committee was formed for each of the issues areas included in the strategy document. The sub-committee members are drawn from the workshop participant lists and are primarily junior level staffs of sectoral agencies and local stakeholders. A secretariat was formed to administer the strategy and to manage the subcommittees. The secretariat is housed at the CDA and staffed by the ICM team.

The CMSC provides a forum for the sectoral agencies to discuss issues that cut across sectoral boundaries. It also gives local stakeholders access to the decision makers and provides them a voice in resource management decisions. The CMSC provides the 
necessary, informal, framework for these institutions to learn how to integrate their decision making, and it educates its members about ICM and coastal resource issues. It also provides an institutional structure that can seek donor funding for ICM and collaboratively manage the funding which is received. It is expected that eventually the CMSC will be formalized and serve as the springboard for a national ICM program.

In Zanzibar, the ICM strategy document was adopted at the national workshop and the proposed implementation framework approved. The framework was similar to the one instituted in Kenya. However, because of political changes on the Island after elections in 1995, the implementation framework has not been fully operationalized.

Another key element in the adoption step is identifying and securing funding for implementation (Olsen et al. 1996). In Zanzibar, this was quickly achieved through the Netherlands Assistance to the Department of Environment project (NADE). This project, which was already providing assistance to DOE, agreed to support ongoing ICM activities for up to five years at levels that would have allowed significant progress. However, because of the changing political situation, NADE was suspended.

In Kenya, the chairman and secretariat of the CMSC, working with $\mathrm{CRC}$, helped establish strong links to existing donor projects that could help support the ICM activities. Ongoing activities in Kenya are also being supported by UNEP and USAID/Kenya who are providing modest additional, resources to implement key actions identified in the strategy document and provide core support to the CMSC. This level of funding will help sustain the ICM process, but it is not adequate to move the process to the necessary next level of effort. The chairman and secretariat are also developing formal proposals to solicit donor funding for the planning strategies detailed in the strategy document. 


\section{Implementation}

The CMSC in Kenya is beginning the process of implementing the strategy document. The speed and intensity in which the CMSC moves ahead is greatly influenced by the available levels of funding, which are relatively low. The chair of the CMSC and the secretariat have focused on organizing the committee, sub-committees and gaining consensus on priority actions.

The standing sub-committees were formed by the CMSC to assist organize and implement ICM activities. Each sub-committee will focus on an issue area identified in the strategy document (e.g., water quality, fisheries, critical habitats, and erosion) and is responsible for developing workplans and proposals for each of the actions recommended in the strategy document. As funding becomes available, the appropriate sub-committee should oversee the implementation of ICM actions. Actions items will also be folded into the workplans of the institution represented by the committee and sub-committee members. This will facilitate strategy implementation without external donor funding.

The CMSC and the sub-committee provides the opportunity to make integrated decisions about coastal resource use. Before the formation of the CMSC all decisions were made sectorally without out cross-institution collaboration. The CMSC now provides a forum for institutions to discuss decisions before they are made independently within sectoral agencies. This forum will greatly increase the effectiveness of decision making related to coastal resources allocation and use and facilitate implementation of ICM tools and practices.

To quickly gain experience in the implementation of coastal management activities and to show public commitment to the process, demonstration projects were developed by the 
ICM team and included in the strategy document. Demonstration projects are designed to quickly complete ICM actions that demonstrate the government's commitment to ICM and provide an opportunity for institutions to experiment with ICM implementation. The projects are selected to address specific, salient problems that affect key stakeholders. They are designed to facilitate stakeholder participation and build constituencies for the project. The process also allows the implementing institutions and stakeholders to work together on specific problems. This begins the process of creating trust and mutual understanding.

In October of 1996, the Kenya ICM team completed their first demonstration project installing mooring buoys in the Mombasa Marine Park and Reserve. The team selected that activity because corals in the park were being damaged by careless tourists and their boat anchors and hulls. The buoys, if correctly installed and used, would limit this damage. This project was jointly sponsored by the Netherlands Wetlands Conservation Programme and USAID.

Rather than simply installing the mooring buoys, the installation project was used to build support for marine park management among local constituencies, including the Kenya Wildlife Service (KWS), boat operators, hoteliers, and dive shop owners. Workshops and training were conducted with the local constituency to create a mooring management program in cooperation. Training was used to teach the KWS, the agency responsible for Park Management, how to design and install more efficient moorings, understand the role of moorings in park management, and explore how "positive" enforcement (versus the more traditional "negative" enforcement) could be an effective tool in park management. The workshops facilitated consensus building among opposing stakeholder groups about where mooring should be placed, how they should be used, and what the general operating rules should be for boaters in the area. 
For several parts of the workshop, KWS was joined by local boat operators and hoteliers. The non-threatening training environment allowed boat operators and KWS rangers to share their opinions and ideas openly. Boat operators helped construct the moorings, select the new mooring sites and install the moorings. By working together, everyone's interests were considered and incorporated into the decisions.

Stakeholders worked with KWS to draft a code of conduct pertaining to the use of the newly installed moorings and an educational brochure about the Park and the moorings. Both these products were discussed at formal stakeholders' meeting held on the last day of the training. Several of the suggestions offered by participants resulted in stricter rules than KWS would have proposed on its own. By the end of the meeting the stakeholders approved revised editions of both products. This cooperative process created the necessary stakeholder support for the rules and, as a result, will reduce the level of formal enforcement necessary to implement them.

This simple and inexpensive project solidified a constituency for ICM implementation. It took critical stakeholder groups (boat operators, hoteliers, and dive shops), teamed them with a key implementing agency and provided a cooperative process that resulted in immediate change in the Park, a code of conduct accepted by the group, and improved communications between park users and managers. At the stakeholder workshop on the final day, this demonstration project's success was used to illuminate the potential success the ICM process can achieve and provided an example of how stakeholders can work together with government to solve problems. 


\section{Evaluation}

A technical assistance intervention is planned for June/July 1997 to establish the evaluation framework for the CMSC. The teams did not establish baselines in the pilot sites before the interventions began. However, it is expected that some of the data collected for the strategy document can be used to measure progress and success.

Although no formal monitoring and evaluation framework has been created, the teams continually evaluated their progress and adjusted their approach as necessary. This "adaptive management" style allowed the team to learn from their experiences on a regular basis and adjust the way in which they proceed. Evaluation was done through debriefings that occurred after every public event and at the conclusion of each mission. The teams also held team meetings on a regular basis throughout the project and a recurring agenda item was to assess the project and team's progress and to adjust the workplan accordingly.

\section{Intervention Techniques Applied by the Project}

The underlying goal of each technical assistance intervention was to build capacity, a key attribute of any ICM program, and to make progress on completing an ICM strategy for the pilot site. The following paragraphs describe the key elements of the technical assistance approach used during the project.

\section{Training approach}

Education experts describe and advocate a learning process termed "adult learning techniques or experiential learning." The foundation for these techniques are based on the 
premise that students, adults and children, learn by doing (Kolb, 1974). Lessons are learned and knowledge is gained through an experiential learning cycle. This cycle has been refined by the strategic planner University Associates (1990). Their learning cycle has five steps:

1. Experiencing: the activity phase

2. Publishing: sharing reactions and observations

3. Processing: discussing patterns and dynamics

4. Generalizing: developing real world principles

5. Applying: planning effective use of learning

To facilitate maximum learning by the team members and make rapid progress on developing the strategy document, the project intervention approach was designed as if it were a large training program, and each mission completed a session of the training program. Each session of the training program focused on a different step in the ICM policy process. Between each session, team members had homework which had to be completed in order for the entire "class" to move forward. All the session designs were based on the adult learning theories of Kolb and University Associates and the experiential learning cycle. Information was presented by the technical advisors and "experienced" by the participants. This information and experience was "published" and "processed" as the team used the information in group exercises. The exercises allowed participants to reflect on the experience. The teams then "generalized" the experience by designing their own field activity and applied the experience in the pilot site what they were learning in the classroom. More importantly, the exercises that the teams completed contributed directly to the completion of their ICM strategy. The "experience" was real and the teams had to live with the outcomes of the "exercise." 
For example, after several days of focusing on critical ICM issues - what they "typically" are, how to define them, how to identify and describe them - the team went into the field to apply what they had learned. At the end of this session, the teams had experienced many of the activities that need to be completed in the first step in the ICM policy process. During this learning experience, they also had collected information that could used in their strategy document.

This process was repeated for each step of the policy process. It facilitated rapid progress on the strategy document because the teams could use information collected during the "training" for the actual strategy document. It also facilitated learning because the team members were constantly completing the learning cycle, moving from experience to application several times during each mission.

Using training as an intervention technique was an effective method for collecting the information needed for the strategy document. It was also very effective in building a unified team. Creating ICM teams with the capacity to work inter-sectorally on ICM issues was an important goal of this project. By using the training approach, the individual team members were forced to work together and build a common experience. This shared experience became the foundation for a ICM constituency in both countries.

By the end of the first mission, the teams had developed a good profile of ICM issues. By the end of the second mission, the issues had been revised by stakeholder groups. By the end of the third mission a first draft of the strategy document was completed which included a refined set of issues and action and planning strategies. This rapid progress gave the teams a sense of accomplishment at the end of each mission and contributed to project's momentum. It also provided the teams something tangible - outlines, drafts, workshop proceedings - that they could share with the growing ICM constituency. 
Technical Assistance as Facilitator and Motivator

One significant issue that has to be overcome by many multiple intervention projects is maintaining the team's focus and momentum. Often, large ICM projects have the resources to pay team members as project staff or place a technical advisor in-country for an extended period of time. Because the East Africa project had a limited time frame and did not have resources to support the team members full time, members had to participate in the process in addition to their normal work responsibilities. In most instances this meant more work without additional remuneration. This was addressed, in part, by providing honoraria for team members. This was made possible through the UNEP EAF/5 program. The honorarium, although small, allowed the team members to work on the project instead of holding another, outside job.

Although the monetary remuneration was an important factor for maintaining the team's focus, it was not the only one or perhaps even most important factor. The teams stayed actively involved because there were empowered and understood the potential of ICM. By the end of each mission, all of the outputs and decisions being generated were owned by the national team. Although the technical advisors expressed concerns when they felt the teams' decisions may not have been most appropriate, and provided examples of similar situations they had dealt with from previous work experience the teams, as the local experts, ultimately made the final decisions. Therefore, the job of the technical advisors was an external information broker, catalyst and facilitator of the teams' work. 


\section{Building a Core ICM Team}

Before initiating the ICM process in Kenya and Zanzibar ICM teams were established. The teams were formed by the team leader in both places. Early designation of core interinstitutional, inter-disciplinary teams who are committed to the project; then providing explicit orientation, training, and group building for that team was critical to the project's success. Team members were drawn from government institutions that have some relationship to ICM.

The project, during the first year, invested a significant amount of time building skills and knowledge of the team. Most of the team members had a solid background in technical areas; but they lacked ICM experience. Therefore, the project focused on developing a core group who understood the need for ICM and the process. This group, over the months became a close knit team that was able to problem solve in an integrated way. They also became strongly committed to the philosophy of ICM and its potential and, therefore, became advocates for ICM in their country. From this nucleus, an ICM constituency was created using the team's web of connections and linkages to other people and organizations.

Using teams instead of individuals or single provided important flexibility and adaptiveness. When one person could not participate in an exercise, there were other team members to complete the necessary work. Several times during the project a team member was shifted to another job or left the country for additional training and education. Having a team offset these changes to personnel and allows the process to continue without interruption. 
Having the FAO funding available for honoraria was an important factor contributing to team building. Without this funding, the team members would likely have had to find work outside of their normal government responsibilities and, therefore, would have dedicated less time to the project. Although it is unlikely that this would have caused the project to collapse, it would have almost certainly have slowed down the planning process.

International Training and Exposure for Team Members

To quickly build the team's ICM capacity, two team members from each country participated in the University of Rhode Island's Summer Institute conducted by the Coastal Resources Center. This month long, intensive training course, introduces participants to the critical elements of ICM drawing from CRC's twenty five year experience in the US and internationally. This initial training, which occurred before the first technical mission, was extremely important. It provided the participating team members an overview of the CRC approach and philosophy and created an opportunity for CRC's technical advisors to begin developing working relationships with them. These relationships were critical during the first mission because the technical advisors had a shared experience and philosophy with someone when they arrived in country. This decreased the amount of start-up time needed at the beginning of the mission. This method of capacity development was so important, two more team members, one from each country, was sent to the next Summer Institute two years later.

The team leaders were also given the opportunity to travel to the US and meet with other ICM experts. This connected the team connection with the international ICM community. It also gave them the sense that they were part of a larger, global effort, to use ICM to reduce coastal problems. While in the US, they also traveled to URI and to 
Washington DC to meet with large NGOs with an interest in East Africa. These meetings also contributed to the stature of the individuals and the country's effort towards ICM.

These international experiences also served to build strong personal relationships and trust between the team members and the technical advisors. These relationships were critical to the success of the project, especially when there was confusion or conflict between the ICM teams and advisors. 


\section{REFLECTION}

This chapter takes a reflective look back at and highlights the important elements the East Africa project. It explores the application of the project's critical elements, such as strategic decision making and following the ICM process, and provides advice on how to improve these elements in future applications. This chapter will also discuss how the East Africa project has contributed to the planner's understanding of contemporary/strategic planning.

\section{Strategic Decision Making}

This project focused strategically on critical issues that were relevant to the pilot site and had salience at the national level. The issues were defined by the local stakeholders then compared to issues of national importance. Issues that were important to both levels were selected for further analysis. The project then narrowed the issues one more step by selecting only those that could be adequately defined and addressed in a short period of time. Issues that were out-of-the range of the team's capacity and resources were avoided.

This strategic approach enabled the teams to complete this project in a relatively short period of time and produce the desired outputs and impacts (e.g., institutional commitment, constituency for ICM, stakeholder participation and awareness). Considering its modest level of resources, the project needed to act strategically. Otherwise, its outputs would have either been broad and diffuse or focused on a technical solution to a single issue. For instance, the project could have focused on completing a detailed land use analysis with only one local institution working closely with technical advisors. This would have possibly created a useful document, but would not likely have 
created a constituency that supported the document and, like many outputs of technical assistance interventions, it would probably not have been implemented. The strategic approach to ICM created both a useful document that is being implemented and a constituency for ICM. This foundation will serve both countries well into the future.

\section{Selecting the pilot site}

The pilot sites were also strategically selected based on the issues they contained, the range of stakeholders groups living and working in the site and importance of the site to the country. The size of each site was kept small for both logistical and operational reasons - the team needed to be able to drive through the entire site in one day, and the site needed to be no larger then necessary to include the key issues and stakeholders. In retrospect, less time and energy should have been spent on defining the pilot sites borders. Instead a 'fuzzy' border should have been formed that included an area large enough to contain the important issues and small enough to be manageable. A finer definition is not necessary because the delineation has no legal significance. Future applications should overtly use the issues to define the boundary instead of defining a boundary and then describing the issues within that area.

\section{Strategic outputs focused on action}

The project's outputs were strategically selected and sorted by immediate and long term activities. By sorting the implementation actions, the teams had an immediate action agenda that was developed around site specific needs and the their capabilities to address those needs. It also gave the teams a longer term workplan that can direct future investment. 
It was clearly stated from the beginning of the project that the output would not be a coastal management plan. Instead the project focused on demonstrating the ICM process and building capacity. This approach has provided a strong basis for future ICM activities and created a process that has significant support from government institutions and local stakeholders.

\section{Using the ICM Policy Process}

Following a series of steps, in this case the CRC policy process steps, was a very important feature of the project. The policy process provided the guide posts for the project and the team to follow. Whenever there was confusion about the next step the team was referred to the policy process. However, it was very important to remind the teams how their actions were an "eddy" of the main process and that although they were making excellent progress on a focused set of issues, they were many years away from completing a first generation ICM program. In future applications of this approach, the team should regularly refer to where they are on the policy process. At a minimum it should be done at the beginning and end of each mission.

These guide posts provided the structural design for the project. Because these guide posts were well established and tested by other ICM projects, they providing the East Africa pilot project credibility and stability. Each mission was designed around a step in the policy process. This provided the technical advisors a framework to guide the entire project and to develop specific activities for each mission.

Experience shows that for ICM to be successful it must contain certain principles and attributes. This project was able to incorporate many of these attributes. Because of the 
project's scope, the attributes were not as visible as in multi-year traditional ICM project. This project, however, did advocate several of the key attributes with vigor because they could easily be accommodated by the process, and they were very important to making the effort successful. The most obvious of these was public participation. This project achieved levels of participation previously unattained in the pilot areas. It was a new experience for local stakeholders to be asked about an issue and then to see their ideas presented in the formal strategy document. Other key attributes that were incorporated into the project included linking the two tracks of government, using good science to make informed decisions, and building capacity and constituency for ICM.

One drawback of this fast moving project is that it did not allow enough time to plan for the initial project activities with the team leaders and lead institutions. Because of the short time frame and limited resources, the process was designed and implemented quickly with minimal input from the team leaders. Ideally, it would have helped to have a planning mission prior to the start of the actual work. This would have provided the technical advisors to see the pilot sites and gain some context about the situation before starting the exercises with the teams. This situation was partially mitigated by having the team leader from Zanzibar attend the Summer Institute before the project missions began. The Kenya Team leader did not attend the Summer Institute. This resulted in a greater start-up time and slightly more confusion during the first mission to Kenya, which probably could have been minimized if the Kenya team leader also attended the Summer Institute.

The lead institution played a key role in the success of the project. It was fortunate that the institutions selected by the design team were capable of guiding the process and were committed to developing an ICM strategy. In retrospect, it may have been prudent if the lead institutions were selected after the first mission or after the proposed planning 
mission. This would provide the technical advisors time to evaluate the institution's leadership, commitment and capacity.

\section{Intervention Techniques}

\section{Training}

The strategic approach to ICM combined the best elements of adult learning with the ICM process to form an excellent intervention style. Training provides a set of tools, skills and attitudes related to the particular training topic. Adult learning suggests that students learn after applying the new tools and reflecting upon the experience (Kolb, 1974).

For future application of this technique, exercises should intensely focus on moving rapidly towards the desired outputs. Each part of the training should either review the theoretical framework for the activities team members must carry out to achieve the desired outputs or actually spend time completing the activities. The more successful sessions provided an opportunity for the team members to test their skills and knowledge in a classroom environment, receive feedback, then re-apply the skills in the field. The extent to which the theoretical framework for ICM must be presented will depend on the audience and must be evaluated within the first few days of the initial mission.

The training approach was also an excellent catalyst for creating a unified, cohesive group that acted like a team with a common mission and purpose. It also allowed the technical advisors easily to assess the group's level of ability and understanding early in the process and design subsequent missions to accommodate those levels. 
Another benefit of the training approach was that the teams learned, passively by observing, how to conduct training programs and deal with common training situations. It provided them with very practical tools such as how to use flip charts effectively, how to organize meeting rooms and how to develop and maintain an agenda. These tools were applied as the teams conducted their stakeholder and national workshops and significantly contributed to the success of those workshops.

\section{Building Teams}

The project could not have completed as much as it did without using a team approach. The teams provided a critical mass for the project and enough people to keep the process moving ahead even with changes in team composition. The team members also became ICM advocates within their home institution. Because they worked in different institutions, they were able to spread information about ICM much further then if the project only worked with one institution or person.

It was important that the teams were made up of enough members to form a critical mass. It was also helpful to have more then one person from the lead institution to provide assistance to the team leader. In the future, it would be beneficial to include team members not associated with government. This was attempted in Kenya, but because of work requirements the hotel representative was not an active team member. This situation needs to be addressed in future applications.

The key to each team was the team leader. These leaders were both high ranking within their institution and respected outside of their institutions. Both served as the critical liaison with agency and stakeholder leaders, assumed responsibility for the process and 
its ramifications. The team leaders also played the role of liaison with the second, national track of government.

\section{Contribution to Contemporary Comprehensive/Strategic Planning}

There are strong similarities between ICM and contemporary/strategic planning. They both share long and short term time horizons, ensure significant community participation, and place a heavy emphasis on action defined by key issues. However, there are some differences between ICM and contemporary/strategic planning. These differences are not fundamental differences in approach but are more closely related to the extent in which certain features and attributes are promoted.

Most notably, ICM places a heavy emphasis on a process that may or may not have plans as an outcome. ICM works on issues within a spatial area defined by the stakeholders. The strategic planning approaches discussed earlier still focus heavily on what the product will be and what it will contain. Although there has been a great shifted way from viewing comprehensive plans as a product, there is still a great deal of attention given to their elements, such as the land use map because of the regulatory nature of the map.

Another difference is that strategic and comprehensive planning also work within a regulatory framework or set of bounds that prescribe what must be done by the planner and planning process. As pointed out by Bryson, this is especially true for comprehensive planning $(1988,8)$. ICM, especially in developing countries, often works in an environment that does not have requirements for planning. In fact, many places where ICM is practiced, the institutional structure of planning is non-existent or 
extremely weak. To complicate matters, institutions responsible for implementation lack the mechanisms to allow inter-sectoral planning. 


\section{CONCLUSION}

Innes (1996) and Kaiser and Godschalk (1995) outline a contemporary approach to comprehensive planning that share many attributes of strategic planning. Examples of ICM, such as the East Africa case study, show that ICM shares many of the attributes this contemporary planning style. ICM demonstrates a process that can lead to immediate change on the ground as well as developing a long term vision and future, both goals of comprehensive and strategic planning.

By the official end of the East Africa pilot project both teams had written an ICM strategy document that described critical coastal problems and pressures for their pilot site, presented short and long term actions for addressing those issues, and provided an implementation framework for moving the strategy document into an action program. Today, the teams have made progress on solving immediate issues. This is highlighted by the Kenya team's efforts to reduce coral damage in the marine park by installing mooring buoys. The teams are also poised for additional investment and have a well organized strategy for guiding that investment.

Comparing the project's impacts with the original goals, the project achieved the following:

- facilitated learning between the local and the national level based on the experience gained in the pilot site. The Kenya team leader is now recognized as a leading ICM practitioner and is regularly asked to inform high level government officials on the status and direction of Kenya's coastal management efforts. 
- built an intersectoral team for ICM and raised capacity of its members. When the project first began, there was a very thin understanding of the ICM process and principles. The teams can now clearly describe the ICM process and principles after applying them in the field during the last three years.

- completed the ICM policy process for the pilot site in an abbreviated time frame. The teams completed the CRC policy process in about two years, instead of the eight to ten years for a first generation program. Although the teams did not create a national program, they initiated the ICM process in their country and set the stage for further action.

- developed an ICM strategy document that identified actions that could be taken immediately and future plans and actions that will be necessary to address coastal resource problems and pressures in the future. In Kenya, one immediate action project has already been completed and several more will be done by the Fall of 1997 . The CMSC is actively seeking donor support for ICM and working with the sectoral institutions to get activities incorporated into institutional workplans.

The ICM approach applied in Kenya and Zanzibar demonstrates that in a relatively short period of time, an ICM team can identify critical issues, make early progress on resolving those issues, and develop a longer term view about how future investments should be made. It also demonstrates that this can be done with significant and meaningful stakeholder input from all levels of government and non-government organizations.

Today, both Kenya and Zanzibar have a framework for action which can facilitate action by providing a framework to guide future, external investment in ICM. It also can be used to motivate the existing institutional structure to incorporate some ICM actions into their existing workplans and to move forward without external funding. In either 
situation, Kenya and Zanzibar are poised to make progress on developing an ICM program that can resolve the growing pressures and problems found in their coastal regions. 


\section{REFERENCES}

Akiwumi, Paul. 1996. Keynote address at the Experts and Practitioners Workshop on Integrated Coastal Management. Tanga, Tanzania. August, 1996.

Altshuler, Alan. 1965a. The City Planning Process: A Political Analysis Cornell University Press: Ithaca, NY.

Altshuler, Alan. 1965b. The Goals of Comprehensive Planning. Journal of American Institute of Planners. 31, 3: 186-97.

Bryson, John M. 1988. Strategic Planning for Public and Nonprofit Organizations: A Guide to Strengthening and Sustaining Organizational Achievement. Jossy-Bass Inc., Publishers: San Francisco.

Casella, Sam. 1993. A Quantum Response to Non-Euclidian Planning. Journal of the American Planning Association 59, 4: 485.

Constandinides, Glafkos. 1993. Bamburi Case Study. PAP/RAC: Croatia.

Crawford, Brian and J. Stanley Cobb and Chou Loke Ming (ed). 1995. Educating Coastal Managers: Proceedings of the Rhode Island Workshop. W. Alton Jones Campus. March 4-10, 1995. Coastal Resources Center: Narragansett.

Friedmann, John. 1993. Toward a Non-Euclidean Mode of Planning. Journal of the American Planning Association 59, 4: 482-5. 
GESAMP (IMO/FAO/UNESCO-IOC/WMO/WHO/IAEA/UN/UNEP Joint Group of Experts on the Scientific Aspects of Marine Environmental Protection), (in press), The Contributions of Science to Integrated Coastal Management, GESAMP Reports and Studies No 61.

Goodstein, Leonard, Timothy Nolan, and J. William Pfeiffer. 1992. Applied Strategic Planning: An introduction. Pfeiffer and Company: San Diego.

Johnson, O., V. Dailey, and C. Frantz.. 1994. Information Please Almanac: Atlas and Yearbook. Houghton Mifflin Company: NY

Innes, Judith E. 1996. Planning Through Consensus Building, A new View of the Comprehensive Planning Ideal. Journal of the American Planning Association 62, 4: 460-472.

Kaiser, Edward J., and David R. Godschalk. 1995. Twentieth Century Land Use Planning, A Stalwart Family Tree. Journal of the American Planning Association 61, 3: 365-385.

Kent. T. J. 1964. The Urban General Plan. San Francisco: Chandler Publishing Company. 1991. 2nd Edition. Planners Press, American Planning Association: Chicago, IL.

Kenya Integrated Coastal Management Team. 1995. Towards Integrated Management and Sustainable Development of Kenya's Coast: Findings and recommendations for an Action Strategy in the Nyali-Bamburi-Shanzu Area. Coast Development Authority: Mombasa, Kenya. 
Kolb, David A. 1974. Learning and Problem Solving; on management and the learning process. from Kolb, David A., Irwin M Rubin, and James M. McIntyre. (ed) Organizational Psychology (second edition). Prentice-Hall, Inc.: Englewood Cliffs.

Lauber, Daniel. 1993. The More Things Change.... Journal of the American Planning Association 59, 4: 486.

Lindblom, Charles E. 1959. The Science of Muddling Through. Public Administration Review 19:79-88.

Meyerson, Martin. 1956. Building the Middle-Range Bridge for Comprehensive Planning. Journal of the American Institute of Planners 22, 2: 58-64.

Olsen, Stephen and George Seavey. 1983. The State of Rhode Island Coastal Resources Management Program (as amended). Coastal Resources Center: Narragansett.

Olsen, Stephen and James Tobey, Donald Robadue, and Emilio Ochoa. 1996. Coastal Management In Latin America and the Caribbean: Lessons Learned and Opportunities for the Inter-American Development Bank. (in press). Draft report prepared for the Inter-American Development Bank: Washington, D.C.

Olsen, Stephen and Lynne Hale. 1994. Strategic Design and Initiation of a Coastal Management Program Participant Workbook. Summer Institute in Coastal Management. Coastal Resources Center: Narragansett. 
Organization for Economic Co-Operation and Development (OECD). 1996-7. World Resources. http://OECD.

Pernetta, J. and D. Elder. 1993. Cross-Sectoral, Integrated Coastal Area Planning (CICAP): Guidelines and Principles for Coastal Area Development. IUCN: Gland, Switzerland.

Pollnac, R. B., J. Pereira, M. Cohen, and G. Trelles. 1994. Rapid Appraisal of Sociocultural Variables Associated With Coastal and Marine Resource Management. Paper Presented at the 5th International Symposium on Society and Resource Management, Fort Collins, CO. 7-10, June 1994.

Sorensen, Jens. 1993. The International Proliferation of Integrated Coastal Zone Management Efforts. Oceans and Coastal Management 21, 1: 45-80.

Swedish Agency for Research Cooperation with Developing Countries (SAREC). SAREC Regional Marine Science Program: A Presentation.

United Nations Conference on Environmental and Development. 1992. Agenda 21: Programme of Action for Sustainable Development. United Nations: New York. United Nations Environmental Programme (UNEP). 1984. Socio-economic activities that may have an impact of the East African region: National Reports. UNEP: Nairobi.

University Associates, Inc. 1990. The Experiential Learning Cycle. Pfeiffer and Company: San Diego. 
Webster, Jim. 1994. Conserving Biodiversity in Africa: A Review of the USAID Africa Bureau's Bio-diversity Program. USAID: Washington, DC.

The World Bank. 1996. Africa: A Framework For Integrated Coastal Zone Management. Land, Water and Natural Habitats Division; The World Bank: Washington, DC.

Zanzibar Integrated Coastal Management Team. 1995. Towards Integrated Management and Sustainable Development of Zanzibar's Coast: Findings and recommendations for an Action Strategy in the Chwaka Bay-Paje Area. Department of Environment: Zanzibar. 